\title{
TE LO PIDO POR FAVOR: ESTRATEGIAS DE CORTESÍA DE HABLANTES DE HERENCIA DEL ESPAÑOL MEXICANO
}

\author{
PRETTY PLEASE: CORTESY STRATEGIES OF HERITAGE SPEAKERS OF MEXICAN SPANISH
}

\section{Chelsea Escalante}

Universidad de California, Davis

Resumen

El presente estudio analiza la realización de peticiones de 30 alumnos universitarios que han adquirido el español como lengua de herencia y compara sus estrategias de cortesía lingüística con las estrategias producidas en las peticiones de 30 nativo-hablantes del norte de México. Este análisis se realiza en el momento en que estos alumnos se enfrentan con la tarea de escribir a interlocutores hipotéticos que representan diferentes grados de poder y distancia social. Las peticiones se analizan de acuerdo a cuatro medidas de cortesía lingüística: (1) la forma de tratamiento, (2) la franqueza del acto principal, (3) el uso de las estrategias de cortesía positiva y (4) el uso de las estrategias de cortesía negativa. Se observa que los participantes siguen la norma monolingüe en cuanto al tratamiento y la formación del acto principal de la petición, exhibiendo variación estilística según las dinámicas de poder y distancia social del interlocutor, pero que hay diferencias sutiles en el uso de estrategias positivas y negativas en comparación a los nativo-hablantes, lo cual apoya la inclusión de la instrucción pragmática explícita en la enseñanza de español como lengua de herencia.

Palabras clave: hablantes de herencia, lengua heredada, pragmática, petición, cortesía
Abstract

The present study investigates the formation of petitions of 30 university students who have acquired Spanish as a heritage language, comparing their strategies of linguistic courtesy with those seen in the petitions of 30 nativespeakers from northern Mexico. The formation of the petition is analyzed as they are faced with writing to hypothetical interlocutors using four different measures of linguistic courtesy: (1) form of address, (2) directness of the head act, (3) use of positive courtesy strategies, and (4) use of negative courtesy strategies. Results suggest that participants follow the monolingual norm with respect to form of address and the formation of the head act, exhibiting stylistic variation according to the dynamics of power and social distance of the interlocuters, but that there are subtle differences in the use of positive and negative strategies in comparison to the native-speakers, which supports the inclusion of explicit pragmatics instruction in the teaching of Spanish as a heritage language.

Key words: heritage speakers, heritage language, pragmatics, petition, courtesy 
Te lo pido por favor: estrategias de cortesía de hablantes de herencia del español mexicano | Chelsea Escalante

\section{$1 \quad$ INTRODUCCIÓN}

Las normas que subyacen al conocimiento de los hablantes acerca de lo que se considera apropiado decir y a quién en relación a sus circunstancias varían considerablemente de una comunidad lingüística a otra, tanto entre grupos idiomáticos diferentes, como también en el interior de los mismos (Dumitrescu, 2006). Las personas que crecen en una situación de contacto lingüístico se enfrentan con la gran tarea de manejarse entre los sistemas pragmáticos de dos lenguas a la vez. De hecho, Kagan (2012) menciona que los hablantes de herencia $(H H)$ - las personas que tienen una conexión personal o familiar a una lengua minoritaria - se agobian con una "carga intercultural», esto es, que tienen que saber manejarse entre los prejuicios culturales, las actitudes y las filosofías que rodean los idiomas. A pesar del peso de esta tarea, durante la última década, la gran mayoría de investigaciones en el campo de lenguas de herencia se ha centrado en la pérdida de rasgos gramaticales (Montrul, 2008; 2009; 2010; Montrul y Bowels, 2009; 2010; Montrul, Bhatt y Benmamoun, 2015; Polinsky, 2006; 2008a; 2008b; 2008c; 2011) y en las faltas que existen en el repertorio léxico de estos hablantes (Isurin \& Ivanova-Sullivan, 2008; Kondo-Brown, 2003; Kagan, 2005). Pocas investigaciones han explorado la competencia pragmática que poseen los bilingües y el proceso de manejar los sistemas pragmáticos de sus dos (o más) lenguas a la vez.

La meta del presente estudio es discutir la competencia pragmática de un grupo de HH de español mexicano en el estado fronterizo de Arizona (EE.UU.), específicamente se analiza cómo realizan el acto de habla de la petición. En las clases de lenguas de herencia en los EE.UU. se enseña un idioma que los estudiantes han adquirido en el hogar y/o en su comunidad inmediata (ReznicekParrado, 2013) y que probablemente usan en contextos limitados debido al predominio de la lengua mayoritaria fuera de la casa (véase Montrul, 2012). La intención del estudio es explorar las herramientas pragmáticas que emplean los $\mathrm{HH}$ en sus peticiones y en el nivel de cortesía lingüística que demuestran cuando se enfrentan a diferentes dinámicas de poder y distancia social con sus interlocutores. Para ofrecer un análisis contrastivo se comparan estos resultados con los de 30 nativo-hablantes de español en una zona geográfica cercana: estudiantes universitarios en el norte de México.

\section{MARCO TEÓRICO}

En el campo de la adquisición de lenguas extranjeras se acepta mayormente que para tener éxito con un idioma, no es suficiente que el hablante logre solamente competencia gramatical y un conocimiento del lexicón de ese idioma; es necesario que también tenga competencia comunicativa y específicamente, competencia pragmática, o el conocimiento de saber qué se considera apropiado decir a quién en qué circunstancias (Mwinyelle, 2005). Una de las maneras en que se manifiesta la competencia pragmática es a través de la cortesía lingüística, definida como una forma de interacción social que se condiciona por las normas socioculturales de una sociedad en particular (Félix-Brasdefer, 2006: 2159). Dado que la cortesía es un rasgo dependiente de las variaciones culturales propias de cada idioma, la transferencia inadecuada de ella se podría resultar en la presencia de intermitencias o incluso la ruptura en el canal de comunicación (Ballesteros Martín, 2001: 172). 
Te lo pido por favor: estrategias de cortesía de hablantes de herencia del español mexicano | Chelsea Escalante

Según Goffman (1967), todos los humanos tienen una imagen («face») que queremos proyectar al público. Esta imagen se determina emocionalmente y puede perderse, mantenerse o mejorarse durante el transcurso de una interacción. Naturalmente, tenemos el deseo defensivo de querer salvaguardar nuestra propia imagen, al mismo tiempo, también poseemos el deseo de proteger la imagen del interlocutor (Goffman, 1972). Entre todas las expresiones lingüísticas de una conversación, algunas de ellas arriesgan la imagen del interlocutor - entre ellas se encuentran la petición, la disculpa, el cumplido y el agradecimiento. En estas expresiones con frecuencia se distingue el valor semántico y el valor pragmático; por lo tanto, requieren que el oyente interprete más que lo que tendría que hacer en una expresión donde el valor semántico y el valor pragmático fueran iguales. Durante la interpretación, si el oyente espera un cierto nivel de cortesía y no lo recibe, la situación puede resultar en un malentendido o un fracaso comunicativo.

Basándose en la teoría de Goffman (1967, 1972), Brown y Levinson (1987) observan que todos los humanos tienen deseos semejantes de salvaguardar su imagen. Estos autores distinguen entre dos aspectos de la imagen que consideran universales: el aspecto positivo y el aspecto negativo. La imagen positiva se refiere al deseo por parte de cada adulto competente de recibir aprobación o agradecimiento. Además, es el deseo de que sus gustos sean agradables, por lo menos, para algunas personas. Por otro lado, la imagen negativa se refiere al deseo de ser libre de imposición y libre de decidir por sí mismo; en otras palabras, es el deseo de que sus acciones no sean refrenadas por los demás (Brown y Levinson, 1987). Si tenemos en cuenta las dos imágenes del interlocutor, estas sostienen que el interlocutor tiene la habilidad de reflejar cortesía verbal a través de estrategias que atienden a la imagen positiva del oyente (estrategias positivas) - es decir, estrategias que hacen que sienta aprobación, que se sienta agradecido y sus deseos sean agradables - o a través de estrategias que atienden a la imagen negativa del oyente (estrategias negativas) - estrategias que hacen que se sienta libre.

Dado que algunas interacciones exhiben en mayor grado la posibilidad de arriesgar la imagen del interlocutor. Brown y Levinson (1987) se refieren a estos actos de habla como actos amenazantes a la imagen («face-threatening acts»). Si el hablante decide realizar un acto amenazante tiene la opción de (1) emitir abiertamente el acto, sin ningún tipo de atenuación, (2) mitigar el acto con estrategias de cortesía positiva, (3) mitigar el acto con estrategias de cortesía negativa o (4) emitir el acto de forma sinuosa o encubierta ${ }^{1}$.

\begin{tabular}{|l|l|l|}
\hline Estrategias positivas & Estrategias negativas & Estrategias encubiertas \\
\hline $\begin{array}{l}\text { Prestar atención al receptor (a sus } \\
\text { intereses, deseos, necesidades y } \\
\text { bienes) }\end{array}$ & $\begin{array}{l}\text { Ser convencionalmente indirecto } \\
\text { Usar la modificación } \\
\text { Ser pesimista }\end{array}$ & $\begin{array}{l}\text { Hacer insinuaciones } \\
\text { Dar pistas por asociación } \\
\text { Presuponer }\end{array}$ \\
\hline
\end{tabular}

\footnotetext{
${ }^{1}$ La teoría de Brown y Levinson (1987) ha recibido crítica en varias áreas, en particular por ser incapaz de evitar una «predisposición etnocéntrica» hacia las lenguas occidentales y la perspectiva occidental (Adelman y Lustig, 1981; Blommaert, 1988; Ferguson, 1981; Tannen, 1985; Watts, 1989; Wierzbicka, 1985a; 1985b; 1991). Trosberg (1994) también explica que la crítica más severa viene de los investigadores de lenguas asiáticas (Doi, 1981; Gu, 1990; Ide, 1989; Matsumoto, 1989) quienes la consideran incapaz de explicar las normas de cortesía en esas culturas donde la cortesía está más relacionada con el rol del individuo en la sociedad y menos con la idea del mantenimiento de la imagen. Además, Scollon y Wong Scollon (2001) critican la teoría de Brown y Levinson por su elección de terminología; dicen que los términos "cortesía positiva» y "Cortesía negativa» pueden ser confusos para el lector y pueden resultar en el malentendido que la cortesía positiva sea buena y la cortesía negativa mala (p. 47). Por esta razón, sugieren el uso de dos términos más apropiados: involucro («involvement») - el deseo de ser un miembro de la sociedad que contribuye a ella y que apoya a los demás - e independencia («independence») - el deseo de mantener la individualidad de uno mismo (p. 46).
}

Normas (ISSN: 2174-7245)|

https://ojs.uv.es/index.php/normas/index

Diciembre 2017 | Volumen 7 | Número 2 | Pág.275 
Te lo pido por favor: estrategias de cortesía de hablantes de herencia del español mexicano | Chelsea Escalante

\begin{tabular}{|c|c|c|}
\hline $\begin{array}{l}\text { Exagerar el interés, la aprobación, } \\
\text { o la simpatía hacia el receptor } \\
\text { Acrecentar el interés del receptor } \\
\text { Utilizar marcadores de identidad } \\
\text { gregaria } \\
\text { Buscar el acuerdo } \\
\text { Evitar el desacuerdo } \\
\text { Presuponer y defender una } \\
\text { perspectiva común } \\
\text { Bromear } \\
\text { Manifestar el conocimiento y la } \\
\text { preocupación del emisor por los } \\
\text { deseos del receptor } \\
\text { Hacer ofertas, promesas } \\
\text { Ser optimista } \\
\text { Incluir ambos, al emisor y al } \\
\text { receptor en la actividad } \\
\text { Dar o pedir razones } \\
\text { Asumir o asegurar la reciprocidad } \\
\text { Hacer concesiones al receptor } \\
\text { (bienes, simpatía comprensión, } \\
\text { cooperación) }\end{array}$ & $\begin{array}{l}\text { Minimizar el rango de la } \\
\text { imposición } \\
\text { Mostrar deferencia } \\
\text { Pedir disculpas } \\
\text { Impersonalizar } \\
\text { Catalogar el acto como una regla } \\
\text { de carácter general } \\
\text { Nominalizar la expresión del acto } \\
\text { Mostrar abiertamente que se } \\
\text { contrae una deuda de } \\
\text { agradecimiento con el receptor. }\end{array}$ & $\begin{array}{l}\text { Ser comedido } \\
\text { Sobreestimar, exagerar } \\
\text { Utilizar tautologías } \\
\text { Utilizar contradicciones } \\
\text { Ser irónico } \\
\text { Utilizar metáforas } \\
\text { Utilizar preguntas retóricas } \\
\text { Mostrar ambigüedad } \\
\text { Utilizar la vaguedad } \\
\text { Generalizar } \\
\text { Reemplazar al receptor } \\
\text { Ser incompleto, utilizar la elipsis }\end{array}$ \\
\hline
\end{tabular}

Tabla 1. Estrategias de cortesía según el modelo de Brown y Levinson (1987) ${ }^{2}$

El modelo de Brown y Levinson (1987) propone que las estrategias de cortesía positiva y negativa son universales, pero admite que las diversas culturas las pueden interpretar de manera distinta. Sin embargo, no discute el rol de los factores de poder y distancia social entre los interlocutores. Por ejemplo, puede ser que las estrategias de cortesía positiva, como hacer chistes o usar marcadores gregarios, no se interpreten como cortesía cuando el hablante está en una conversación con alguien desconocido o cuando uno de los interlocutores está en una posición de autoridad. De manera parecida, la estrategia negativa de mostrar deferencia puede que no se considere apropiada en una situación en la que los dos hablantes son amigos cercanos. Por esta razón, Scollon y Wong Scollon (2001) y Félix-Brasdefer (2005) han criticado el modelo anterior al exponer que las estrategias de cortesía no son universales por el hecho de que no aplican a todas las situaciones cuando se tiene en cuenta el tipo de relación que existe entre los interlocutores. Ellos sugieren que hay tres sistemas separados de cortesía, cada uno con su manera de explicar la cortesía cuando entran las dos variables de poder $(P)$ y distancia social (D): (1) el sistema de cortesía jerárquica $(+P,+D),(+P,-D)$, (2) el sistema de cortesía deferencial $(-P,+D)$ y (3) el sistema de cortesía de solidaridad (-P, $-D)$. En el primer sistema, uno de los dos interlocutores se encuentra en una posición de superioridad y el otro en una de inferioridad en términos de poder. En este sistema, la distancia social entre los dos puede ser cercana (-D) o lejana (+D). Un ejemplo de una situación de (+P, -D) podría consistir en un jefe y su empleado o un profesor y su alumno. Por otro lado, la relación entre un padre y su hijo se podría clasificar como (+P, -D) ya que hay desigualdad de poder pero cercanía relacional ${ }^{3}$. En el segundo sistema, los dos interlocutores se consideran del mismo nivel social pero tienen una

\footnotetext{
${ }^{2}$ Las estrategias de cortesía positiva, negativa, y encubiertas en la teoría de Brown y Levinson fueron escritos en inglés. Aquí utilizo las traducciones de Ballesteros Martín (2001, p. 184) de estos términos al español.

${ }^{3}$ Las relaciones mencionadas se proveen como ejemplos pero no se pretenden implicar que no exista variación acerca de las variables de poder y distancia en todas las relaciones.
}

Normas (ISSN: 2174-7245) | 
Te lo pido por favor: estrategias de cortesía de hablantes de herencia del español mexicano | Chelsea Escalante

relación con distancia social $(+D)$. Un ejemplo de este tipo de sistema podría ser dos compañeros de trabajo o de clase; aunque no hay una brecha de poder entre los dos, tampoco participan en una relación socialmente cercana. En el tercer sistema, los dos se consideran de igual nivel social (P) y participan en una relación de poca distancia social (-D). La relación de dos hermanos, primos o amigos podría ser clasificada bajo este tipo de sistema. El presente estudio adopta este modelo porque consideramos importante la distinción de poder y distancia y las manifestaciones en el habla de los interlocutores de sus percepciones de estas variables.

Una contribución de Blum-Kulka (1989) al campo de la cortesía lingüística es su categorización de los actos principales de la petición. Dentro del modelo de Brown y Levinson (1987), se menciona bajo las estrategias de cortesía negativa la de usar indireccionalidad convencional ("conventional indirectness»). Se puede deducir, por tanto, que el modelo supone que las peticiones indirectas presentan mayor cortesía que las directas. Sin embargo, no provee la oportunidad de explorar otro tipo de petición: la pista/insinuación. Blum-Kulka (1989) ofrece un nuevo modelo que considera una gama más amplia de la formulación de la petición que incluye este tipo de petición.

\begin{tabular}{|c|c|c|}
\hline $\begin{array}{l}\text { Nivel de franqueza del acto } \\
\text { principal de la petición }\end{array}$ & Tipos & Ejemplos \\
\hline Directo & $\begin{array}{l}\text { Imperativo } \\
\text { Performativo } \\
\text { Descripción de un } \\
\text { deseo o necesidad }\end{array}$ & $\begin{array}{l}\text { Préstame tus apuntes } \\
\text { Te pido que me prestes tus } \\
\text { apuntes } \\
\text { Necesito que me prestes tus } \\
\text { apuntes }\end{array}$ \\
\hline Indirecto convencional & Sugerencia & $\begin{array}{l}\text { ¿Qué te parece si me prestes tus } \\
\text { apuntes? }\end{array}$ \\
\hline Indirecto no-convencional & Pista & $\begin{array}{l}\text { Necesito los apuntes y eres el } \\
\text { único que conozco }\end{array}$ \\
\hline
\end{tabular}

Tabla 2. Estrategias de cortesía usadas en las peticiones según la franqueza del acto principal (Blum-Kulka, 1989)

En comparación con el modelo de Brown y Levinson (1987) que solamente considera la petición indirecta convencional, este modelo ofrece un análisis más detallado de las diferencias en los tres tipos básicos de peticiones.

\section{ESTUDIOS PREVIOS}

\subsection{La cortesía lingüística en el español como lengua nativa}

Según Pinto y Raschio (2007), la petición ha sido uno de los actos de habla más estudiados. Curcó (1998) compara las percepciones de cortesía en el acto de la petición entre los españoles y los mexicanos y encuentra que los mexicanos tienden a prestar mayor atención a salvaguardar la imagen positiva del interlocutor que los españoles. Utilizan con mayor frecuencia los marcadores tradicionalmente asociados con la expresión de cortesía positiva - sufijación diminutiva, las preguntas interrogativas - y también exhiben la tendencia a evitar el uso de los imperativos sin mitigación. 


\section{normas}

Te lo pido por favor: estrategias de cortesía de hablantes de herencia del español mexicano | Chelsea Escalante

Félix-Brasdefer (2005) realiza un estudio sobre las estrategias de cortesía usadas en las peticiones entre participantes mexicanos. Utilizando la clasificación de las peticiones de Blum-Kulka (1989), Félix-Brasdefer examina las estrategias según sus modificaciones externas e internas. Estas modificaciones siguen un modelo propuesto por Færch y Kasper (1989) que incluye modificaciones externas como los elementos léxicos (diminutivos, la frase por favor, verbos mentales como creer) o elementos sintácticos (condicional, imperfecto). Como modificaciones internas incluye los elementos compasivos opcionales (razones, frases preparativas y frases desarmantes). El estudio también considera las diferentes dinámicas de poder y distancia; de las cinco situaciones que se les presentan a los participantes, dos son de $(+P,+D)$, dos son de $(-P,+D)$ y la última es de $(-P,-D)$. Se encuentra que los participantes prefieren las peticiones indirectas convencionales en situaciones de $(+P,+D)$ mientras que prefieren las directas en situaciones de menor distancia social (-D). Concluye que la formación de las peticiones directas depende de la situación, pero parecen ser la elección más adecuada en un sistema de cortesía de solidaridad (-P, -D).

\subsection{La cortesía lingüística en el español como lengua de herencia}

En comparación a la cantidad de estudios pragmáticos de monolingües, son pocos los estudios que han investigado la competencia pragmática de los $\mathrm{HH}$. En términos generales se ha propuesto que uno de los rasgos más salientes de los $\mathrm{HH}$ se encuentra en la falta de conocimiento de las normas pragmáticas (Kagan, 2012), especialmente en relación al uso de formas apropiadas para llevar a cabo interacciones en contextos formales. Kagan (2012) también menciona que los instructores de español como lengua de herencia reportan que sus alumnos rutinariamente usan la forma familiar tú en vez de usted, y afirma que los «hablantes de herencia no son capaces de cambiar su habla con un compañero conversacional que no sea un miembro de su familia o un amigo» (p. 78, traducción mía). Este autor propone como evidencia datos de hablantes de ruso como lengua heredada que pragmáticamente no responden de manera adecuada a la hora de dejar un mensaje telefónico a su profesor en una situación hipotética en la cual explican el motivo por faltar a un examen. En particular, se observan tres áreas donde los hablantes señalaban una falta de normas discursivas en la lengua de herencia: (1) el tratamiento que usaban con el profesor; (2) sus explicaciones largas y detalladas de por qué faltaban el examen; y (3) sus comentarios sobre la fecha en que les convendría retomar el examen (en vez de esperar las indicaciones del profesor de una posible fecha futura). Kagan enfatiza que esas normas varían de cultura a cultura y la transferencia de normas de una cultura a la otra (a veces inapropiadamente) es algo normal para cualquier hablante de otra lengua. Sin embargo, menciona que, dada la buena pronunciación y fluidez de los $\mathrm{HH}$, muchas veces están sujetos a un estándar más alto y por lo tanto, los errores pragmáticos que cometen pueden causar fricción en sus relaciones con sus profesores, las cuales que no ocurren en las relaciones entre los profesores y sus alumnos no-nativos (Kagan, 2012: 79).

En términos más específicos a la formación de la petición, sabemos poco. Arellano (2000), en su estudio sobre las peticiones usadas en el habla de bilingües mexicanoamericanos de California, encuentra una preferencia hacia el uso del imperativo con por favor en comparación al imperativo solo. Asimismo, concluye que el nivel de autoridad es significativo en estas interacciones; los participantes utilizan con mayor frecuencia las peticiones indirectas y las palabras de mitigación con interlocutores que tienen altos niveles de autoridad.

Pinto y Raschio (2007), estudian las peticiones de hablantes monolingües de inglés y español además de un grupo de $\mathrm{HH}$ de español, encuentran que los bilingües tienden a emplear menos 


\section{normas}

Te lo pido por favor: estrategias de cortesía de hablantes de herencia del español mexicano | Chelsea Escalante

estrategias directas que los monolingües hispanohablantes. Sugieren por tanto, que la tendencia entre los monolingües mexicanos de usar estrategias directas en situaciones de mayor confianza y solidaridad y la preferencia hacia las estrategias indirectas en inglés parece crear un conflicto para los bilingües que están entre los dos sistemas. Dado que estos participantes se sitúan dentro del ámbito bilingüe, pero se inclinan hacia el dominio del inglés frente al español, existe una tendencia de favorecer las estrategias usadas por los monolingües de inglés.

Finalmente, en cuanto al uso de tú/usted entre los bilingües, Brown (1975) reporta que los hablantes bilingües de ascendencia mexicana en Arizona usan usted con sus padres en un porcentaje que es el doble que la que existe entre los monolingües mexicanos, lo que sugiere un sistema más conservador de preferencia pronominal en la comunidad bilingüe.

\section{MÉTODOS}

\subsection{Participantes}

El presente estudio se basa en datos de 60 hablantes de español: 30 nativo-hablantes de español del norte de México y 30 hablantes avanzados de español como lengua heredada (de una variedad mexicana) alumnos universitarios en el estado de Arizona. El grupo de nativo-hablantes consiste en 30 participantes que crecieron en el norte de México y en el momento de recoger los datos todos habían estudiado en universidades mexicanas en los estados de Chihuahua, Sonora y Sinaloa. Todos nacieron en México con la excepción de un participante que nació en Los Ángeles, California, y vivió allí hasta los cuatro años. Las edades de los 16 hombres y 14 mujeres oscilaban entre 18 y 37 años, pero la mayoría (21) tenían entre 20 y 29 años. El grupo de $\mathrm{HH}$, todos de ascendencia mexicana, crecieron durante gran parte de sus vidas en los Estados Unidos y, por lo general, adquirieron el español en el dominio familiar. Estos alumnos fueron escogidos por haberse matriculado en clases avanzadas (de tercer año) diseñadas específicamente para HH y se verificó su estatus como $\mathrm{HH}$ a través de un cuestionario que se les preguntó sobre su historia lingüística y su proceso de adquisición de ambos idiomas, español e inglés. De los 30 participantes de este grupo, 23 eran mujeres y 7 hombres. Todos tenían entre 19 y 27 años; la mayoría tenía entre 19 y 21 años (27 estudiantes), mientras que sólo tres personas tenían más de 21 años. En términos de sus propias perspectivas de etnicidad/nacionalidad, la mayoría de los participantes se autoidentificaron como «mexicano-americano» (20), seguido por «mexicano» (7). Solamente tres alumnos reportaron pertenecer a un grupo no-especificado ("otro»), y ninguno reportó ser del grupo caucásico. Aunque la mayoría (20) de los participantes nunca habían vivido fuera del país, diez habían pasado un año o más en México. De estos participantes, 7 nacieron en México y vivieron allí hasta mudarse a los EE.UU. entre la edad de 5 años (en los casos de inmigración más temprana) hasta la edad de 18 años (en el caso de inmigración más reciente). Tres participantes nacieron en los EE.UU. pero se fueron a vivir a México por un periodo de entre 1 y 6 años durante su niñez.

\subsection{Instrumento}

Cada participante completó un cuestionario de respuesta libre disponible por medio de internet. El cuestionario presentaba al participante cuatro situaciones distintas y le pedía que escribiera un correo electrónico respondiendo a cada situación. En la primera situación el participante tenía que escribir un correo electrónico a su profesor pidiéndole que le diera una extensión para la entrega de un trabajo final. En la segunda, tenía que escribirle a su papá pidiéndole 200 dólares para cubrir 
Te lo pido por favor: estrategias de cortesía de hablantes de herencia del español mexicano | Chelsea Escalante

gastos inesperados. En la tercera situación, tenía que escribirle a su compañero de clase pidiéndole que le pasara la tarea de un día que faltó al aula. Por último, tenía que escribir a su mejor amigo pidiéndole que pasara a recogerlo para ir a una fiesta juntos. Las cuatro situaciones fueron clasificadas según los parámetros de Scollon y Wong Scollon (2001) por su nivel de poder y distancia social ${ }^{4}$ :
1. Situación 1 - profesor: $(+P,+D)$
2. Situación 2 - padre: $(+P,-D)$
3. Situación 3 - compañero de clase: $(-P,+D)$
4. Situación 4 - mejor amigo: $(-P,-D) 5$

\subsection{Análisis}

Los datos fueron codificados según cuatro tipos de análisis: (1) forma de tratamiento (tú vs. usted); (2) el nivel de franqueza del acto principal de la petición (directo, indirecto convencional, indirecto no-convencional); (3) estrategias de cortesía positiva; y (4) estrategias de cortesía negativa. Las estrategias de cortesía positiva y negativa (mencionadas en Figura $1^{6}$ ) se adoptaron de la teoría de Brown y Levinson (1987) con algunos cambios por cuestiones de aplicabilidad al estudio, ya que este no es un intercambio cara-a-cara. Se incluyen los cuatro análisis - que son las diferentes maneras en las que podemos manifestar la cortesía lingüística - para conocer más a fondo los patrones de cortesía empleadas por los HH y su comparación con los nativo-hablantes. Después de codificar los datos se llevó a cabo un análisis estadístico de regresión logística multinomial de los datos usando el programa SPSS.

\section{RESULtados}

\subsection{La cortesía según forma de tratamiento}

La meta del primer análisis fue explorar el uso de tú y usted (junto a sus formas correspondientes) de cada grupo y en cada situación hipotética para entender mejor cómo los participantes se expresaron a la hora de enfrentarse con diferentes niveles de poder y distancia social. El análisis estadístico revela que hay diferencias significativas en el tratamiento por situación $\left(x^{2}=773.319, p\right.$ $<0.001$, df $=3)$, pero no por grupo $\left(x^{2}=1.659, p=0.198, d f=1\right)$; es decir, que los HH y los nativohablantes son sensibles a las dinámicas de poder y distancia, y usan tú y usted en contextos distintos. Sin embargo, no hay diferencias significativas entre cómo emplean marcadores de tratamiento los $\mathrm{HH}$ en comparación a los nativo-hablantes. Se observa en los dos grupos la preferencia hacia el uso de usted con el profesor y tú con los demás interlocutores: el padre, el compañero y el amigo. El comportamiento de los nativo-hablantes sugiere que en el norte de México

\footnotetext{
${ }^{4}$ La clasificación del nivel de poder y distancia social de las situaciones hipotéticas se basan en generalizaciones que no necesariamente se reflejen en las relaciones interpersonales verdaderas de los participantes. Aunque está fuera del alcance del artículo hablar de la complejidad de las dinámicas de poder y distancia social en las interacciones, la autora es consciente de que el nivel de poder y distancia social se definen de manera diferente para cada persona en cada contexto y no son fijos como se presentan en este estudio. Sin embargo, fue necesario crear situaciones hipotéticas siguiendo generalizaciones para ver la sensibilidad estilística de los participantes.

${ }^{5}$ Las situaciones 1, 3 y 4 vienen del trabajo de Félix-Brasdefer (2005) que utiliza el mismo tipo de clasificación, pero en este estudio se agregó la situación del padre para crear un sistema de (+P, -D), ya que no fue incluido en el trabajo mencionado.

${ }^{6}$ Se decidió no incluir las estrategias encubiertas del modelo de Brown y Levinson (1987) en este análisis por razones de ambigüedad ya que para la mayoría se requiere conocimiento de las intenciones del interlocutor.
}

Normas (ISSN: 2174-7245) | 
Te lo pido por favor: estrategias de cortesía de hablantes de herencia del español mexicano | Chelsea Escalante

existen normas consistentes que rigen el tratamiento: en situaciones de $(+P,+D)$ se prefiere la variable formal, pero en situaciones de $(+P,-D),(-P,+D)$, y $(-P,-D)$ se prefiere la variable informal. El comportamiento de los $\mathrm{HH}$ sugiere que este grupo haya adquirido las mismas normas de tratamiento de la zona monolingüe geográficamente más cercana.

\begin{tabular}{|l|l|l|l|l|}
\hline & & tú N(\%) & usted N(\%) & Total \\
\hline Nativos & Profesor & $0(0)$ & $110(100)$ & 110 \\
\hline & Padre & $100(93.5)$ & $7(6.5)$ & 107 \\
\hline & Compañero & $120(100)$ & $0(0)$ & 120 \\
\hline & $\begin{array}{l}\text { Mejor } \\
\text { amigo }\end{array}$ & $69(100)$ & $0(0)$ & 69 \\
\hline Total & & $289(71.2)$ & $117(28.8)$ & 406 \\
\hline $\mathrm{HH}$ & Profesor & $8(6.8)$ & $109(93.2)$ & 117 \\
\hline & Padre & $103(92.8)$ & $8(7.2)$ & 111 \\
\hline & Compañero & $76(100)$ & $0(0)$ & 76 \\
\hline & $\begin{array}{l}\text { Mejor } \\
\text { amigo }\end{array}$ & $79(98.7)$ & $1(1.3)$ & 80 \\
\hline Total & & $176(59.9)$ & $118(40.1)$ & 294 \\
\hline
\end{tabular}

Tabla 3. Tratamiento por grupo y contexto

Los bilingües siguen los mismos patrones que los nativos, ya que prefieren los mismos pronombres en cada contexto. Aunque hay mayor desacuerdo entre participantes para este grupo, no llega a un nivel estadísticamente significativo.

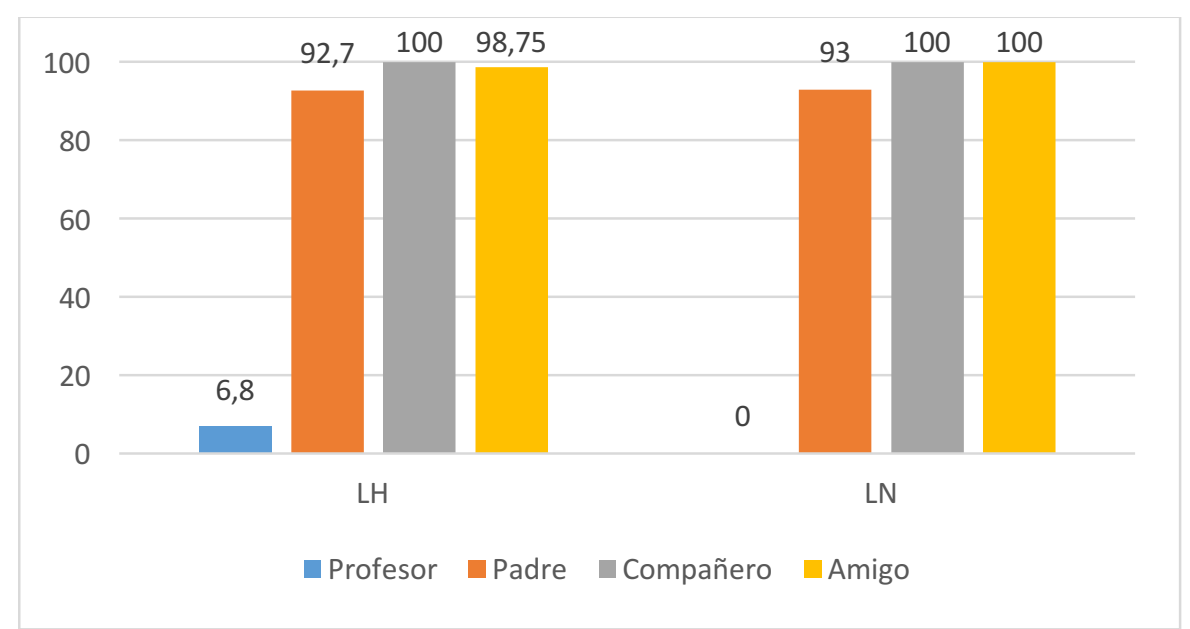

Figura 1. Uso de formas informales por grupo y contexto

Si miramos las peticiones de cerca, nos damos cuenta de una diferencia sutil entre los $\mathrm{HH}$ frente a los nativo-hablantes. Encontramos en los $\mathrm{HH}$ algunos instantes de cambio de referente dentro del mismo discurso. En los ejemplos 1a-1c se observa una preferencia hacia el uso de usted, pero en un instante el participante cambia a usar una forma correspondiente a tú. En el ejemplo 2, ocurre lo 


\section{normas}

Te lo pido por favor: estrategias de cortesía de hablantes de herencia del español mexicano | Chelsea Escalante

contrario; se emplean formas correspondientes a la variante informal, pero en un instante se utiliza una forma correspondiente a la variante formal ${ }^{7}$.

(1a) Ha ocurrido una emergencia entre la familia y no podre entregar el proyecto final a tiempo. Le pido por una extensión de una semana. Por favor dejame saber en cuanto tenga tiempo. Que tenga buen día, Estudiante de espanol 323. $(\mathrm{HH}, 4)$

(1b) Hola maestro de econiomia quiero dicirle que no voy a poder estar en clase entonce no podre entregar mi poryecto. La razon es porque tengo un emerigenica en mi familia. La \"policy\" dice que no pudo entregarlo nomas quise decirle mi situacion y se me puedes ayudar. $(\mathrm{HH}, 7)$

(1c) Hubo una emergencia en mi familia y tengo que regresar a casa inmediatamente para estar con mis familiares. Yo se que temeos entregarle nuestro proyecto final muy pronto pero yo necesitare entregarselo depues de devolver. Si hay un problema o necesita hablarme, llamame. $(\mathrm{HH}, 10)$

Necesito pedirte si puedes dar me un extension para el proyecto. Mi razon por pedirte esta extencion es porque desafortunadamente mi abuela esta en el hospital en circunstancias muy graves. Gracias por su tiempo. $(\mathrm{HH}$, 23)

Este cambio de referente indica que los desvíos de las normas pragmáticas pueden ser resultados no solo de una falta de conocimiento de las normas mismas (o la decisión consciente de no emplearlas), sino también por fallas gramaticales. Aunque es imposible saber las intenciones del participante, parece que los participantes de los ejemplos (1a-c) tienen la intención de usar usted (lo cual sigue los patrones de los nativo-hablantes y por lo tanto puede ser considerado pragmáticamente apropiado), pero, a diferencia de los nativos, su sistema gramatical no insiste en que se mantenga el mismo referente a través del discurso. El cambio de referente les lleva a desviarse de las normas monolingües usando tú en contextos donde los nativos prefieren usted. Estos resultados sugieren que las instancias de desacuerdo a las normas no necesariamente reflejan una falta de competencia pragmática, sino también pueden reflejar una flexibilidad en la gramática de los bilingües que no existe en la variedad monolingüe.

\subsection{La cortesía según el nivel de franqueza del acto principal de la petición}

En este análisis se examinó la formación del acto principal de la petición - si se realizó de forma directa (préstame tus apuntes), indirecta convencional (¿qué te parece si me prestes tus apuntes?) o indirecta no-convencional (necesito los apuntes y eres el único que conozco). Al igual que en el análisis de tratamiento, el análisis estadístico revela que hay diferencias significativas en la formación del acto principal por situación $\left(x^{2}=34.966, p<0.001\right.$, $\left.d f=6\right)$, pero no por grupo $\left(x^{2}=4.873, p=0.087\right.$, $\mathrm{df}=2)$; es decir, que los $\mathrm{HH}$ y los nativo-hablantes son sensibles a las dinámicas de poder y distancia social y forman el acto principal de la petición de manera diferente cuando están en situaciones distintas. Sin embargo, no hay diferencias significativas en la formación de los actos principales entre los $\mathrm{HH}$ y los nativo-hablantes, lo que sugiere que los $\mathrm{HH}$ han adquirido las normas monolingües con respecto a la formación de la petición.

Según los estudios previos, debemos esperar mayor uso de peticiones directas en casos de menor formalidad y distancia social, mientras que el uso de peticiones indirectas muestra casos de mayor formalidad y distancia (Félix-Brasdefer, 2005). Al contrario de los patrones esperados, se observa

${ }^{7}$ Los ejemplos se presentan tal como se recibieron sin ninguna modificación.

Normas (ISSN: 2174-7245)|

https://ojs.uv.es/index.php/normas/index

Diciembre 2017 | Volumen 7 | Número 2 | Pág.282 
una preferencia hacia el uso de las peticiones indirectas convencionales en los cuatro contextos. Esta preferencia es aún más fuerte en la situación con el compañero $(-P,+D)$ donde hay pocas instancias en que se emplea otro tipo de petición. Encontramos interesante que, entre ambos grupos de hablantes, las peticiones directas se emplean más con el profesor - la situación donde se esperaría mayor formalidad. Los resultados están alineados con la teoría de Brown y Levinson (1987) en la que exponen que las peticiones indirectas se consideran de mayor cortesía, aunque no mencionan cómo los factores de poder y distancia afectan a la realización de la petición.

\begin{tabular}{|l|l|l|l|l|l|}
\hline & & $\begin{array}{l}\text { Directo } \\
\mathrm{N}(\%)\end{array}$ & $\begin{array}{l}\text { Indirecto } \\
\text { convencional } \\
\mathrm{N}(\%)\end{array}$ & $\begin{array}{l}\text { Indirecto no- } \\
\text { convencional } \\
\mathrm{N}(\%)\end{array}$ & Total \\
\hline LN & Profesor & $8(26.6)$ & $14(46.6)$ & $8(26.6)$ & 30 \\
\hline & Padre & $11(36.6)$ & $18(60)$ & $1(3.3)$ & 30 \\
\hline & Compañero & $5(17.2)$ & $24(80)$ & $0(0)$ & 29 \\
\hline & Mejor amigo & $13(43.3)$ & $17(56.6)$ & $0(0)$ & 30 \\
\hline Total & & $37(31.1)$ & $73(61.3)$ & $9(7.6)$ & 119 \\
\hline & & & & & \\
\hline LH & Profesor & $8(26.6)$ & $16(53.3)$ & $6(20)$ & 30 \\
\hline & Padre & $7(23.3)$ & $21(70)$ & $2(6.6)$ & 30 \\
\hline & Compañero & $1(3.3)$ & $29(96.6)$ & $0(0)$ & 30 \\
\hline Total & Mejor amigo & $7(23.3)$ & $18(60)$ & $5(16.6)$ & 30 \\
\hline
\end{tabular}

Tabla 4. Nivel de franqueza del acto principal de la petición por grupo y contexto

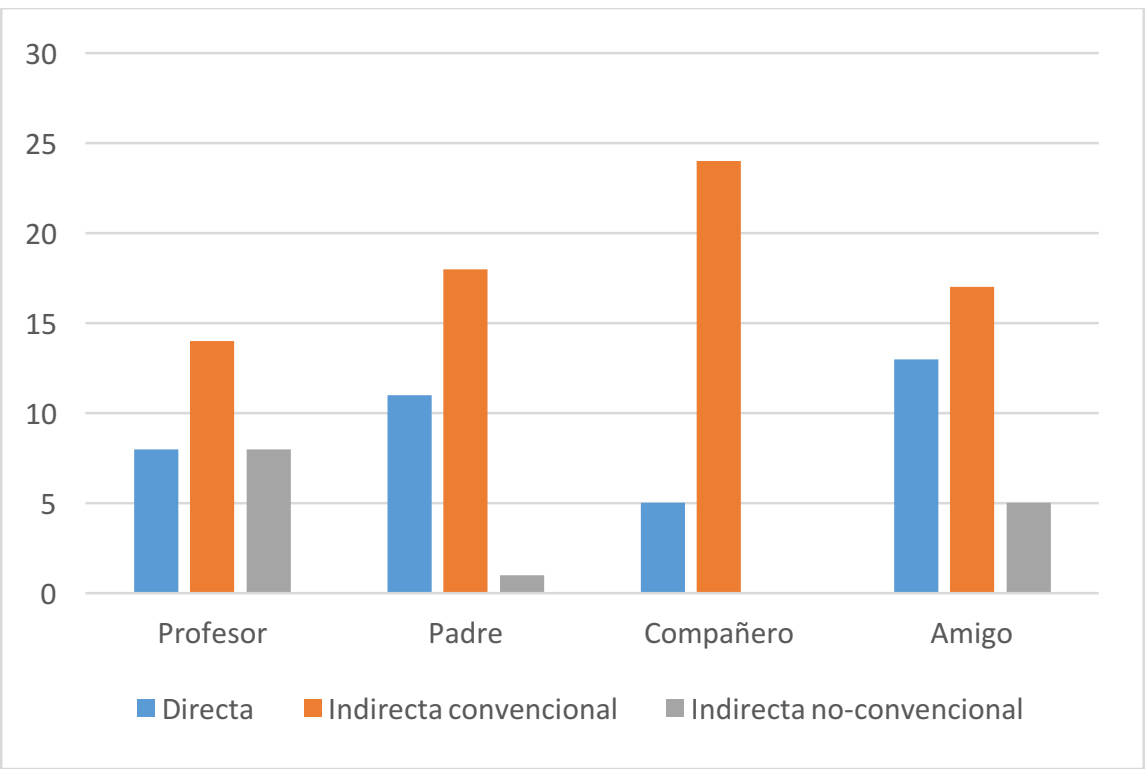

Figura 2. Gráfico de nivel de franqueza del acto principal de la petición por contexto: nativos 


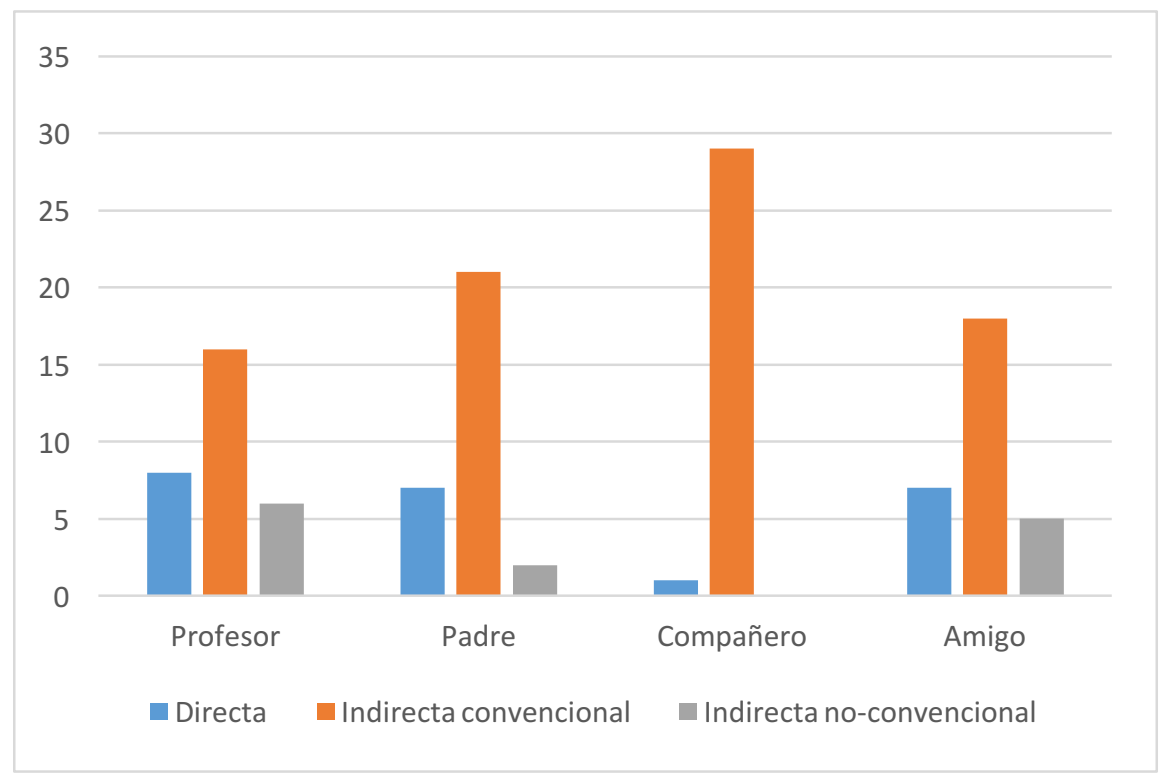

Figura 3. Gráfico de nivel de franqueza del acto principal de la petición por contexto: $H H$

Dado que los hablantes prefieren las peticiones indirectas en todos los contextos, nos surgen unas preguntas importantes. ¿Se construyen las peticiones de igual manera en todos los contextos? ¿Qué otras herramientas usan para responder a las variables de formalidad y distancia social? ¿Son iguales esas herramientas para los $\mathrm{HH}$ que para los nativo-hablantes? El análisis cualitativo de todas las peticiones nos permite ver que la formación de las peticiones directas varía considerablemente entre los diferentes interlocutores. En los ejemplos (3) y (4), el mismo participante utiliza peticiones que se clasifican como directas tanto en la situación con el profesor como con el mejor amigo - dos situaciones opuestas en cuanto a las dinámicas de poder y distancia.

Estimado Profesor de economia, Escribo este correo electronico porque ha ocurrido una emergencia en mi familia. Le pido porfavor que me de la oportunidad de entregar mi proyecto final unos dias despuez de la fecha asignada. Tengo que salir del pais, pero le asuguro que entregare mi proyecto final si usted me lo permite un poco tarde. Gracias, estudiante de economia $(\mathrm{LH}, 16)$

Amigo!!! Mi caro no esta funcionando!!! Otra vez!!! Si todavia quieres que valla contigo a la fiesta, pasa por mi y nos vamos guntos. Que te parese? Te voy a esperar. Chao! (LH, 16)

En estas dos situaciones, aunque ambas peticiones se clasifican como directas, los participantes emplean herramientas lingüísticas en la situación con el profesor (Estimado Profesor, por favor, si me lo permite, etc.) que señalan mayores niveles de formalidad. Estas formas se discutirán más a fondo en la próxima sección, pero es importante destacarlas para subrayar que no se puede concluir necesariamente que los participantes fallan en su competencia pragmática debido a su uso de peticiones directas con el profesor. Al contrario, ambos grupos demuestran que poseen un repertorio amplio de estrategias pragmáticas que les permite mostrar formalidad de distintas maneras. Como se ve en el ejemplo 4, una petición directa se considera adecuada (si se consideran los patrones del grupo de nativos-hablantes como base para decidir adecuación) en situaciones de mayor poder y distancia social si se emplea con otros marcadores de cortesía. 


\subsection{La cortesía según las estrategias positivas}

En esta sección se discute el uso de estrategias de cortesía positiva realizadas por los dos grupos en cada contexto. Recordemos que las estrategias positivas son las que hacen que el oyente se sienta aprobado, agradecido y que sus deseos sean agradables. En este análisis la variable independiente de situación fue un predictor significativo $\left(x^{2}=244.201, p<0.001\right.$, df $\left.=27\right)$, lo que sugiere que los $\mathrm{HH}$ y los nativo-hablantes son sensibles a las dinámicas de poder y distancia social. También había diferencias significativas en el uso de estrategias entre los $\mathrm{HH}$ y los nativo-hablantes $\left(x^{2}=50.650, p<0.001, d f=9\right)$, lo que apunta a que los bilingües tienen un reportorio distinto en comparación a los monolingües.

\begin{tabular}{|c|c|c|c|c|c|c|c|c|c|c|c|c|}
\hline & & $\begin{array}{l}\mathrm{EP}^{8} 1 \\
\mathrm{~N}(\%)\end{array}$ & $\begin{array}{l}\text { EP 2 } \\
N \\
(\%) \\
\end{array}$ & $\begin{array}{l}\text { EP } 3 \\
N \\
(\%)\end{array}$ & $\begin{array}{l}\text { EP } \\
4 \mathrm{~N} \\
(\%)\end{array}$ & $\begin{array}{l}\text { EP } 5 \\
N \\
(\%) \\
\end{array}$ & $\begin{array}{l}\text { EP } 6 \\
\text { N (\%) }\end{array}$ & $\begin{array}{l}\text { EP } 7 \\
N \\
(\%) \\
\end{array}$ & $\begin{array}{l}\text { EP } \\
8 \mathrm{~N} \\
(\%)\end{array}$ & $\begin{array}{l}\text { EP } 9 \\
N \\
(\%) \\
\end{array}$ & $\begin{array}{l}\text { EP10 } \\
N \\
(\%)\end{array}$ & Total \\
\hline \multirow[t]{4}{*}{ Nativos } & Profesor & $\begin{array}{l}17 \\
(21.5)\end{array}$ & $\begin{array}{l}2 \\
(2.5) \\
\end{array}$ & $\begin{array}{l}4 \\
(5.1) \\
\end{array}$ & $\begin{array}{l}0 \\
(0) \\
\end{array}$ & $\begin{array}{l}10 \\
(12.6)\end{array}$ & $\begin{array}{l}4 \\
(5) \\
\end{array}$ & $\begin{array}{l}14 \\
(17.7)\end{array}$ & $\begin{array}{l}0 \\
(0) \\
\end{array}$ & $\begin{array}{l}28 \\
(35.4)\end{array}$ & $\begin{array}{l}0 \\
(0) \\
\end{array}$ & 79 \\
\hline & Padre & $\begin{array}{l}26 \\
(18.9) \\
\end{array}$ & $\begin{array}{l}54 \\
(39.4) \\
\end{array}$ & $\begin{array}{l}2 \\
(1.5)\end{array}$ & $\begin{array}{l}2 \\
(1.5)\end{array}$ & $\begin{array}{l}10 \\
(7.3)\end{array}$ & $\begin{array}{l}7 \\
(5.1) \\
\end{array}$ & $\begin{array}{l}7 \\
(5.1) \\
\end{array}$ & $\begin{array}{l}2 \\
(1.5)\end{array}$ & $\begin{array}{l}27 \\
(19.7)\end{array}$ & $\begin{array}{l}0 \\
(0)\end{array}$ & 137 \\
\hline & Compañero & $\begin{array}{l}21 \\
(17.2) \\
\end{array}$ & $\begin{array}{l}36 \\
(29.5) \\
\end{array}$ & $\begin{array}{l}10 \\
(8.2)\end{array}$ & $\begin{array}{l}3 \\
(2.4) \\
\end{array}$ & $\begin{array}{l}11 \\
(9) \\
\end{array}$ & $\begin{array}{l}4 \\
\text { (3.3) } \\
\end{array}$ & $\begin{array}{l}7 \\
(5.7) \\
\end{array}$ & $\begin{array}{l}6 \\
(4.9) \\
\end{array}$ & $\begin{array}{l}24 \\
(19.7)\end{array}$ & $\begin{array}{l}0 \\
(0)\end{array}$ & 122 \\
\hline & Amigo & $\begin{array}{l}15 \\
(9.4)\end{array}$ & $\begin{array}{l}90 \\
(57)\end{array}$ & $\begin{array}{l}1 \\
(0.6)\end{array}$ & $\begin{array}{l}11 \\
(7)\end{array}$ & $\begin{array}{l}5 \\
(3.2)\end{array}$ & $\begin{array}{l}1 \\
(0.6)\end{array}$ & $\begin{array}{l}1 \\
(0.6)\end{array}$ & $\begin{array}{l}14 \\
(8.9)\end{array}$ & $\begin{array}{l}20 \\
(12.7)\end{array}$ & $\begin{array}{l}0 \\
(0)\end{array}$ & 158 \\
\hline Total & & $\begin{array}{l}79 \\
(15.9)\end{array}$ & $\begin{array}{l}182 \\
(36.7)\end{array}$ & $\begin{array}{l}17 \\
(3.4)\end{array}$ & $\begin{array}{l}16 \\
(3.2)\end{array}$ & $\begin{array}{l}36 \\
(7.2)\end{array}$ & $\begin{array}{l}16 \\
(3.2)\end{array}$ & $\begin{array}{l}29 \\
(5.8)\end{array}$ & $\begin{array}{l}22 \\
(4.4)\end{array}$ & $\begin{array}{l}99 \\
(19.9)\end{array}$ & $\begin{array}{l}0 \\
(0)\end{array}$ & 496 \\
\hline \multirow[t]{4}{*}{$\mathrm{HH}$} & Profesor & $\begin{array}{l}10 \\
(16.1)\end{array}$ & $\begin{array}{l}0 \\
(0)\end{array}$ & $\begin{array}{l}8 \\
(12.9)\end{array}$ & $\begin{array}{l}0 \\
(0)\end{array}$ & $\begin{array}{l}2 \\
(3.2)\end{array}$ & $\begin{array}{l}6 \\
(9.7)\end{array}$ & $\begin{array}{l}6 \\
(9.7)\end{array}$ & $\begin{array}{l}0 \\
(0)\end{array}$ & $\begin{array}{l}30 \\
(48.4)\end{array}$ & $\begin{array}{l}0 \\
(0)\end{array}$ & 62 \\
\hline & Padre & $\begin{array}{l}15 \\
(14.8) \\
\end{array}$ & $\begin{array}{l}32 \\
(31.7) \\
\end{array}$ & $\begin{array}{l}1 \\
(1) \\
\end{array}$ & $\begin{array}{l}2 \\
(2) \\
\end{array}$ & $\begin{array}{l}6 \\
(6) \\
\end{array}$ & $\begin{array}{l}12 \\
(11.9) \\
\end{array}$ & $\begin{array}{l}5 \\
(5) \\
\end{array}$ & $\begin{array}{l}0 \\
(0)\end{array}$ & $\begin{array}{l}28 \\
(27.8) \\
\end{array}$ & $\begin{array}{l}0 \\
(0) \\
\end{array}$ & 101 \\
\hline & Compañero & $\begin{array}{l}0 \\
(0)\end{array}$ & $\begin{array}{l}11 \\
(20)\end{array}$ & $\begin{array}{l}5 \\
(9)\end{array}$ & $\begin{array}{l}1 \\
(1.8)\end{array}$ & $\begin{array}{l}6 \\
(10.9)\end{array}$ & $\begin{array}{l}2 \\
(3.6)\end{array}$ & $\begin{array}{l}3 \\
(5.5)\end{array}$ & $\begin{array}{l}0 \\
(0)\end{array}$ & $\begin{array}{l}25 \\
(45.5)\end{array}$ & $\begin{array}{l}2 \\
(3.6)\end{array}$ & 55 \\
\hline & Amigo & $\begin{array}{l}3 \\
(3.9) \\
\end{array}$ & $\begin{array}{l}28 \\
(36.4)\end{array}$ & $\begin{array}{l}0 \\
(0)\end{array}$ & $\begin{array}{l}5 \\
(6.5) \\
\end{array}$ & $\begin{array}{l}1 \\
\text { (1.3) } \\
\end{array}$ & $\begin{array}{l}1 \\
(1.3) \\
\end{array}$ & $\begin{array}{l}3 \\
(3.9) \\
\end{array}$ & $\begin{array}{l}10 \\
(13)\end{array}$ & $\begin{array}{l}26 \\
(33.8)\end{array}$ & $\begin{array}{l}0 \\
(0) \\
\end{array}$ & 77 \\
\hline Total & & $\begin{array}{l}28 \\
(9.4)\end{array}$ & $\begin{array}{l}71 \\
(24)\end{array}$ & $\begin{array}{l}14 \\
(4.7)\end{array}$ & $\begin{array}{l}8 \\
(2.7)\end{array}$ & $\begin{array}{l}15 \\
(5)\end{array}$ & $\begin{array}{l}21 \\
(7.1)\end{array}$ & $\begin{array}{l}17 \\
(5.7)\end{array}$ & $\begin{array}{l}10 \\
(3.3)\end{array}$ & $\begin{array}{l}109 \\
(36.9)\end{array}$ & $\begin{array}{l}2 \\
(0.7)\end{array}$ & 295 \\
\hline
\end{tabular}

\begin{tabular}{|l|l|}
\hline Clave de códigos \\
\hline Reconocer/atender a los deseos del oyente & Ofrecer/prometer \\
\hline Usar marcadores gregarios & Ser optimista \\
\hline Presuponer lo que hay en común & Incluir ambos en la actividad \\
\hline Hacer chistes & Dar razones \\
\hline Exagerar & Afirmar reciprocidad \\
\hline
\end{tabular}

Tabla 6. Estrategias de cortesía positiva por grupo y contexto

${ }^{8}$ Estrategia positiva (véase la clave de códigos) 


\section{normas}

Te lo pido por favor: estrategias de cortesía de hablantes de herencia del español mexicano | Chelsea Escalante

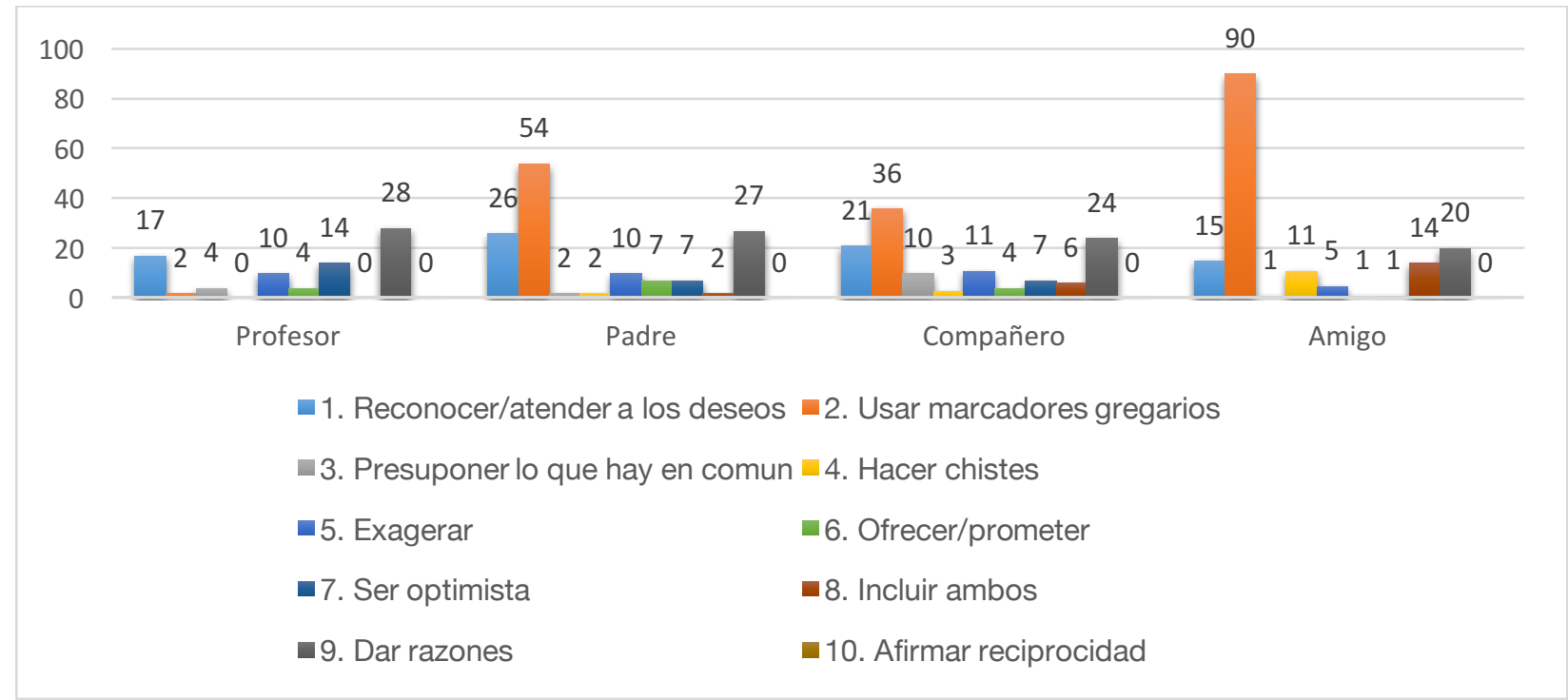

Figura 4. Gráfico de estrategias de cortesía positiva por contexto (nativos)

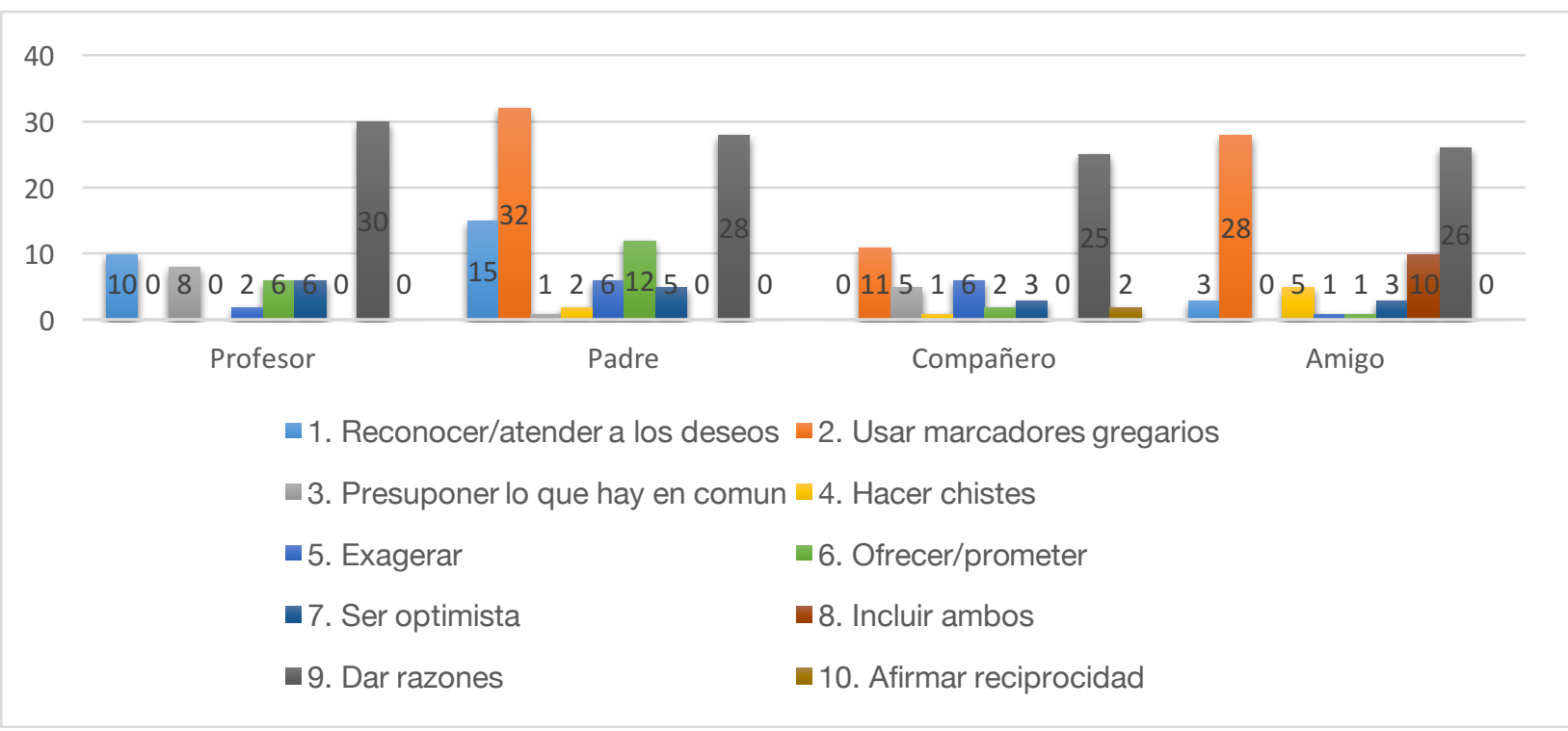

Figura 5. Gráfico de estrategias de cortesía positiva por contexto $(\mathrm{HH})$

El hecho de que los dos grupos tienden a cambiar sus estrategias a un nivel significativo en cuanto al contexto en que se encuentran sugiere que son sensibles a las variables de poder y distancia social y que son capaces de emplear cambios estilísticos de acuerdo al contexto. Aunque Dressler (1982, 1988) propone que el HH posee un repertorio estilístico limitado por haber adquirido la lengua en el dominio familiar, los datos recogidos apoyan la posición contraria de Sánchez-Muñoz (2007), quien sostiene que los $\mathrm{HH}$ no son monoestilísticos; de hecho, poseen un repertorio estilístico amplio parecido al que tiene un monolingüe. Los $\mathrm{HH}$, por ejemplo, emplean las estrategias de atender a los deseos del oyente (ejemplo 5) y dar razones (ejemplo 6) en la situación de mayor formalidad mientras que usan marcadores gregarios (ejemplo 7) en las de menor distancia social, siguiendo los mismos patrones que los nativos. 
Te lo pido por favor: estrategias de cortesía de hablantes de herencia del español mexicano | Chelsea Escalante

(1) Entiendo que esta semana debemos entregar el proyecto de fin de semestre, mas sin embargo ha habido una emergencia familiar que me impidira entregarlo tiempo. Entiendo que solo es justo si lo entrego junto con el resto de mis compañeros pero se me dificulta mucho ya que debo estar al lado de mi familia en estos momentos de crisis. $(\mathrm{HH}, 12)$

(2) Se que el proyecto final se tiene que entregar pronto. Sin embargo, hubo una emergencia en mi familia ya que se murio mi abuela y tuvimos que viajar a Mexico. $(H \mathrm{H}, 22)$

(3) Mensoooo!!! mi carro se fregoo!!! podrias pasar por mi ? k pena ya se k vivo lejos pero ps :S estas cosas pasan... avisame pliiis! teadoro! $(\mathrm{HH}, 17)$

Aparte de demostrar sensibilidad estilística, los $\mathrm{HH}$ y los nativos tienen otra característica lingüística en común: el uso de la alternancia de código como marcador gregario ${ }^{9}$. Como se ve en los ejemplos 8 y 9 , un $\mathrm{HH}$ alterna de código con su padre y otro utiliza una expresión que contiene un calco con su padre. Además, tres participantes utilizan el préstamo bye (ejemplo 10):

(2) Papa! Mi cuenta de dinera ya esta casi llega a 0, todavia tengo otros pagos que hacer. Seria posible que me epositaras dinero en mi cuenta? I love you! $(\mathrm{HH}, 20)$

(3) No pudrieras depositarme 200 dolares para esta semana y luego a mi siguiento cheque yo le pagare para atras? Gracias! $(\mathrm{HH}, 5)$

(4) Te queria pedir si me podias mandar las notas del dia que falte y tambien la tarea que se nesesita entregar? muchas gracias, y si tu nesesitas algo tambien estoy aqui para ayudarte! bye bye $(\mathrm{HH}, 18)$

Aunque Valdés (1981) limita esta estrategia al repertorio de los hablantes bilingües, los resultados de este estudio sugieren que los préstamos no solamente se utilizan entre los participantes bilingües. Los nativo-hablantes también emplean la despedida bye (ejemplo 11a y $11 \mathrm{~b}$ con deletreo alternativo) y además, party (ejemplo 11b).

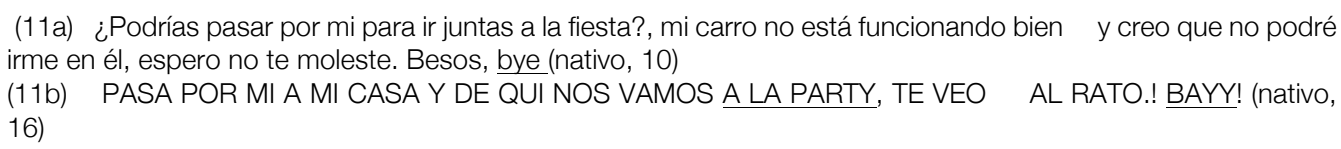

El uso del préstamo léxico, uno de los resultados de lenguas en contacto (Sankoff, 2001), quizás se debe a la influencia que tiene el inglés en el norte de México. Dado que no se ha usado en la situación más formal (con el profesor), pero sí se ha empleado con los demás interlocutores, nos sugiere, que en esta región, los préstamos funcionan para mantener la imagen positiva en relaciones de menor formalidad.

A pesar de tener varias similitudes, los HH también se desvían de los nativo-hablantes en ciertos aspectos. Primero, no han usado la misma cantidad de estrategias en general que los nativos. En total, los nativos usaron 496 diferentes marcadores de cortesía positiva mientras que los bilingües solo 295, aproximadamente un $60 \%$ de la cantidad del otro grupo. Estos resultados probablemente se deben a que los nativos escribieron correos más largos que los bilingües, posiblemente por estar más cómodos con la tarea de escribir en español, lo que favorece una mayor cantidad de marcadores de cortesía.

\footnotetext{
${ }^{9}$ En el análisis se incluyen las instancias de cambio de código bajo la categoría de marcadores gregarios por dos razones: (1) porque este tipo de lenguaje normalmente ocurre en la interacción de dos interlocutores bilingües para marcar que pertenecen al mismo grupo y (2) porque ha sido reportado por Valdés (1981) que los bilingües emplean el cambio de código como estrategia de cortesía.

Normas (ISSN: 2174-7245) | 
Otra diferencia entre los dos grupos se refleja en la distribución de la estrategia de dar razones en comparación a las otras estrategias. Para el grupo de nativo-hablantes, la estrategia de dar razones suma un $19.9 \%$ del total de todas las estrategias usadas, mientras que para los $\mathrm{HH}$ la tasa llega a un $36.9 \%$, lo cual sugiere que los $\mathrm{HH}$ cuentan con esta estrategia más que con las otras. Los nativos, por otro lado, presentan una mayor distribución en el uso otras estrategias.

\subsection{La cortesía según las estrategias negativas}

En esta sección se discuten las estrategias de cortesía negativa que usan los dos grupos. De manera parecida a las estrategias positivas, las negativas también se utilizan por parte del hablante para salvaguardar la imagen del oyente. No obstante, se emplean estas estrategias para hacer creer al oyente que es libre de tomar sus propias decisiones y que sus acciones no están controladas por los demás. En este análisis observamos una variación en los participantes en el uso de estrategias según la situación a un nivel estadísticamente significativo ( $x 2=138.287, p<0.001$, df $=24)$, esto sugiere que son sensibles a las dinámicas de poder y distancia social. También hay diferencias significativas en el uso de estrategias entre los $\mathrm{HH}$ y los nativos $\left(x^{2}=45.798, p<0.001\right.$, $\left.d f=8\right)$, lo cual nos indica que los bilingües tienen un reportorio distinto en comparación con los monolingües.

\begin{tabular}{|c|c|c|c|c|c|c|c|c|c|c|c|}
\hline & & $\begin{array}{l}\mathrm{EN}^{10} 1 \\
\mathrm{~N}(\%)\end{array}$ & $\begin{array}{l}\text { EN } 2 \\
\mathrm{~N}(\%)\end{array}$ & $\begin{array}{l}\text { EN } 3 \\
\mathrm{~N}(\%)\end{array}$ & $\begin{array}{l}\text { EN } 4 \\
N(\%)\end{array}$ & $\begin{array}{l}\text { EN } 5 \\
N(\%)\end{array}$ & $\begin{array}{l}\text { EN } 6 \\
N(\%)\end{array}$ & $\begin{array}{l}\text { EN } 7 \\
N(\%)\end{array}$ & $\begin{array}{l}\text { EN } 8 \\
N(\%)\end{array}$ & $\begin{array}{l}\text { EN } 9 \\
\mathrm{~N}(\%)\end{array}$ & Total \\
\hline \multirow[t]{4}{*}{ Nativos } & Profesor & $\begin{array}{l}8 \\
(7.8)\end{array}$ & $\begin{array}{l}5 \\
(4.9)\end{array}$ & $\begin{array}{l}4 \\
(3.9)\end{array}$ & $\begin{array}{l}28 \\
(27.4)\end{array}$ & $\begin{array}{l}27 \\
(26.5)\end{array}$ & $\begin{array}{l}9 \\
(8.8)\end{array}$ & $\begin{array}{l}10 \\
(10)\end{array}$ & $\begin{array}{l}11 \\
(10.8)\end{array}$ & $\begin{array}{l}0 \\
(0)\end{array}$ & 102 \\
\hline & Padre & $\begin{array}{l}25 \\
(35.7)\end{array}$ & $\begin{array}{l}7 \\
(10)\end{array}$ & $\begin{array}{l}2 \\
(2.8)\end{array}$ & $\begin{array}{l}9 \\
(12.9)\end{array}$ & $\begin{array}{l}19 \\
(27.1)\end{array}$ & $\begin{array}{l}0 \\
(0)\end{array}$ & $\begin{array}{l}4 \\
(5.7)\end{array}$ & $\begin{array}{l}0 \\
(0)\end{array}$ & $\begin{array}{l}4 \\
(5.7)\end{array}$ & 70 \\
\hline & Compañero & $\begin{array}{l}14 \\
(23.3)\end{array}$ & $\begin{array}{l}4 \\
(6.7)\end{array}$ & $\begin{array}{l}3 \\
(5)\end{array}$ & $\begin{array}{l}13 \\
(21.7)\end{array}$ & $\begin{array}{l}22 \\
(36.7)\end{array}$ & $\begin{array}{l}3 \\
(5)\end{array}$ & $\begin{array}{l}1 \\
(1.7)\end{array}$ & $\begin{array}{l}0 \\
\text { (0) }\end{array}$ & $\begin{array}{l}0 \\
(0)\end{array}$ & 60 \\
\hline & Mejor amigo & $\begin{array}{l}7 \\
(15.6)\end{array}$ & $\begin{array}{l}6 \\
(13.3)\end{array}$ & $\begin{array}{l}3 \\
(6.7)\end{array}$ & $\begin{array}{l}11 \\
(24.4)\end{array}$ & $\begin{array}{l}9 \\
(20)\end{array}$ & $\begin{array}{l}1 \\
(2.2)\end{array}$ & $\begin{array}{l}8 \\
(17.8)\end{array}$ & $\begin{array}{l}0 \\
(0)\end{array}$ & $\begin{array}{l}0 \\
(0)\end{array}$ & 45 \\
\hline Total & & $\begin{array}{l}54 \\
(19.4)\end{array}$ & $\begin{array}{l}22 \\
(7.9)\end{array}$ & $\begin{array}{l}12 \\
(4.3)\end{array}$ & $\begin{array}{l}61 \\
(22)\end{array}$ & $\begin{array}{l}77 \\
(27.7)\end{array}$ & $\begin{array}{l}13 \\
(4.6)\end{array}$ & $\begin{array}{l}23 \\
(8.3)\end{array}$ & $\begin{array}{l}11 \\
(3.9)\end{array}$ & $\begin{array}{l}4 \\
(1.4)\end{array}$ & 277 \\
\hline \multirow[t]{4}{*}{$\mathrm{HH}$} & Profesor & $\begin{array}{l}1 \\
(1.5)\end{array}$ & $\begin{array}{l}99 \\
(13.4)\end{array}$ & $\begin{array}{l}0 \\
(0)\end{array}$ & $\begin{array}{l}12 \\
(17.9)\end{array}$ & $\begin{array}{l}34 \\
(50.7)\end{array}$ & $\begin{array}{l}3 \\
(4.5)\end{array}$ & $\begin{array}{l}7 \\
(10.4)\end{array}$ & $\begin{array}{l}1 \\
(1.5)\end{array}$ & $\begin{array}{l}0 \\
(0)\end{array}$ & 67 \\
\hline & Padre & $\begin{array}{l}15 \\
(22.7)\end{array}$ & $\begin{array}{l}2 \\
\text { (3) }\end{array}$ & $\begin{array}{l}3 \\
(4.5)\end{array}$ & $\begin{array}{l}7 \\
(10.6)\end{array}$ & $\begin{array}{l}21 \\
(31.8)\end{array}$ & $\begin{array}{l}1 \\
(1.5)\end{array}$ & $\begin{array}{l}5 \\
(7.6)\end{array}$ & $\begin{array}{l}0 \\
(0)\end{array}$ & $\begin{array}{l}12 \\
(18.2)\end{array}$ & 66 \\
\hline & Compañero & $\begin{array}{l}0 \\
(0) \\
\end{array}$ & $\begin{array}{l}3 \\
(5.7) \\
\end{array}$ & $\begin{array}{l}1 \\
(1.9)\end{array}$ & $\begin{array}{l}14 \\
(26.4)\end{array}$ & $\begin{array}{l}31 \\
(58.5)\end{array}$ & $\begin{array}{l}1 \\
(1.9) \\
\end{array}$ & $\begin{array}{l}1 \\
\text { (1.9) }\end{array}$ & $\begin{array}{l}0 \\
(0) \\
\end{array}$ & $\begin{array}{l}2 \\
(3.8) \\
\end{array}$ & 53 \\
\hline & Mejor amigo & $\begin{array}{l}0 \\
\text { (0) }\end{array}$ & $\begin{array}{l}5 \\
(18.5)\end{array}$ & $\begin{array}{l}0 \\
(0)\end{array}$ & $\begin{array}{l}5 \\
\text { (18.5) }\end{array}$ & $\begin{array}{l}10 \\
(37)\end{array}$ & $\begin{array}{l}5 \\
(18.5)\end{array}$ & $\begin{array}{l}2 \\
(7.4)\end{array}$ & $\begin{array}{l}0 \\
\text { (0) }\end{array}$ & $\begin{array}{l}0 \\
\text { (0) }\end{array}$ & 27 \\
\hline Total & & $\begin{array}{l}15 \\
(7)\end{array}$ & $\begin{array}{l}19 \\
(8.9) \\
\end{array}$ & $\begin{array}{l}4 \\
(1.8)\end{array}$ & $\begin{array}{l}38 \\
(17.8)\end{array}$ & $\begin{array}{l}96 \\
(45)\end{array}$ & $\begin{array}{l}10 \\
(4.7) \\
\end{array}$ & $\begin{array}{l}15 \\
(7) \\
\end{array}$ & $\begin{array}{l}1 \\
(0.4)\end{array}$ & $\begin{array}{l}14 \\
(6.5)\end{array}$ & 213 \\
\hline
\end{tabular}

${ }^{10}$ Estrategia negativa (véase la clave de códigos)

Normas (ISSN: 2174-7245)| 


\begin{tabular}{|l|l|}
\hline Clave de códigos \\
\hline Usar mitigador/diminutivo & Pedir disculpas \\
\hline Ser pesimista & Impersonalizar \\
\hline Minimizar la imposición & Nominalizar \\
\hline Mostrar deferencia & Endeudarse públicamente \\
\hline Dar gracias & \\
\hline
\end{tabular}

Tabla 7. Estrategias de cortesía negativa por grupo y contexto

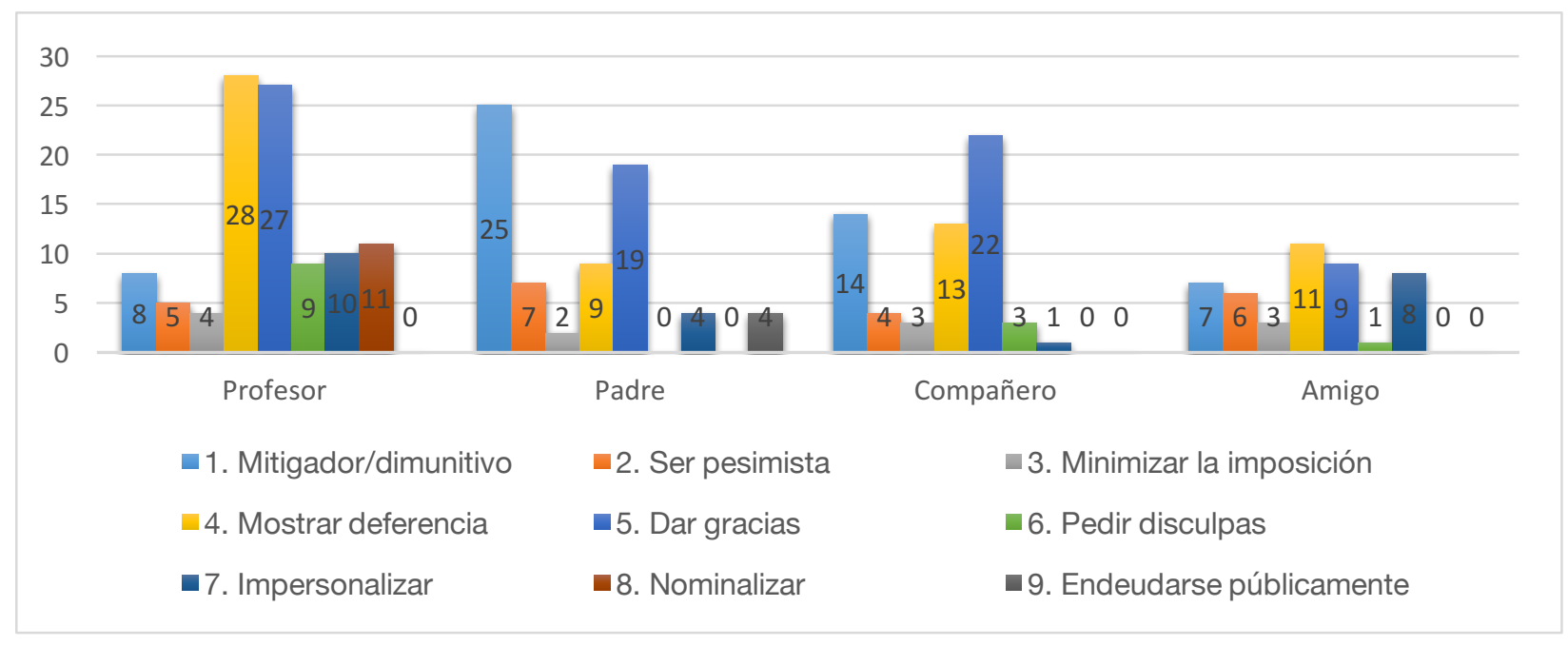

Figura 6. Gráfico de estrategias de cortesía negativa por contexto (nativos)

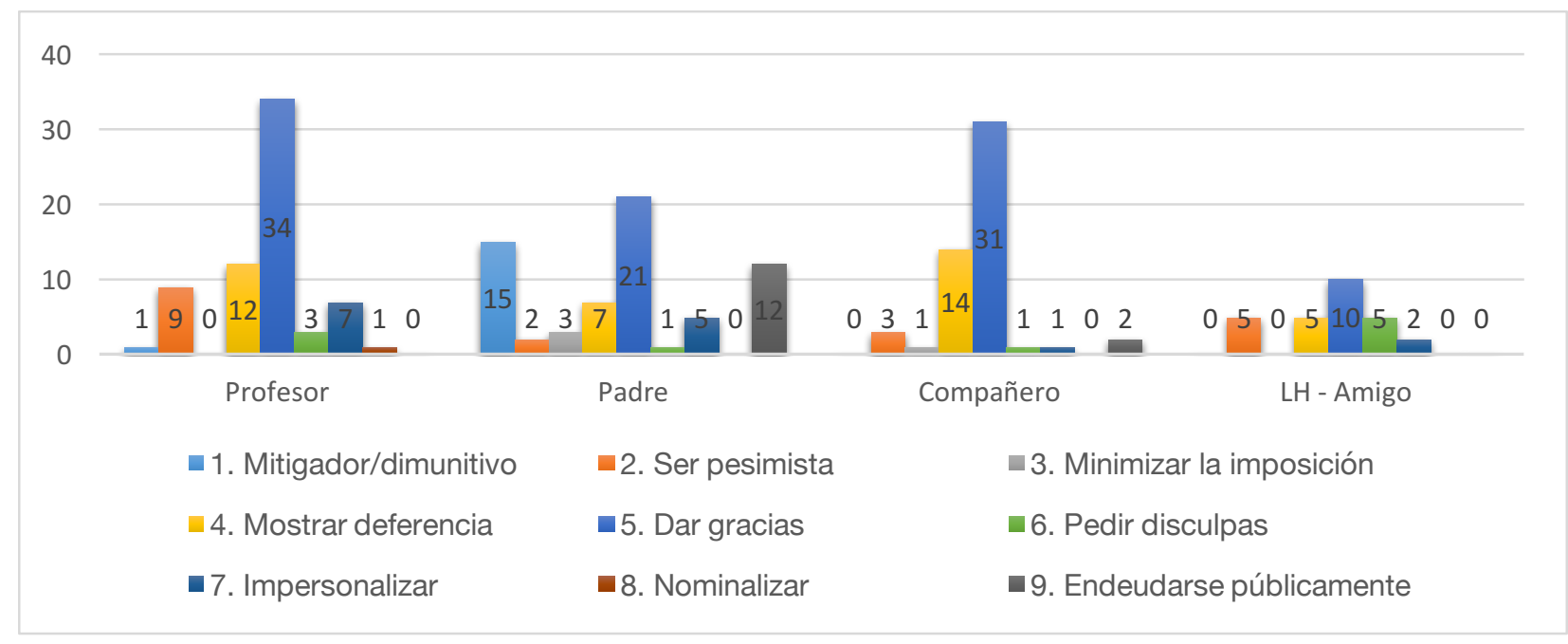

Figura 7. Gráfico de estrategias de cortesía negativa por contexto $(\mathrm{HH})$ 
Te lo pido por favor: estrategias de cortesía de hablantes de herencia del español mexicano | Chelsea Escalante

Los $\mathrm{HH}$ manejan las estrategias negativas de manera parecida a los nativo-hablantes, por ejemplo, también prefieren las estrategias de agradecer (ejemplo 12), de mostrar deferencia (ejemplo 13), y de usar mitigadores/diminutivos (ejemplo 14).

(5) Podrias enviarme un email despues de la clase y dime lo que hicimos y la tarea. Tambien puedes llamarme. Gracias, chiquita :-) (HH, 10)

(6) papa, me falta pagar mi renta para mi departamento este fin de semana pero no tengo suficiente dinero en el banco. Si seras tan amamble a depositarme 200 dolares, y en dos semanas te los repago de veras me ayudaras mucho. $(\mathrm{HH}, 9)$

(7) Solo te mando este corto mensaje para dejarte saber que mi cuenta de cheques esta muy baja y apunto de llegar a \$0. Todavia tengo algunas cuentas que pagar $(\mathrm{HH}, 17)$

A pesar de que los dos grupos favorecen la estrategia de agradecer con todos los interlocutores, la distribución de esta estrategia en comparación a las otras es diferente entre ellos. Entre los nativohablantes, de todas las estrategias usadas en los cuatro contextos, solo un $27.7 \%$ de ellas son de dar las gracias. En comparación, entre los $\mathrm{HH}$ el porcentaje llega a un 45\%. Además, aunque los dos grupos realizan la estrategia de agradecimiento de mayor grado en todos los contextos, es la estrategia preferida en todas las situaciones para los $\mathrm{HH}$, mientras que es la estrategia preferida en sólo uno de los contextos para los nativos (con el compañero). Los resultados sugieren que los nativo-hablantes manejan un repertorio más amplio de estrategias que los $\mathrm{HH}$.

También hay diferencias entre los dos grupos en cuanto a la formación de la frase de agradecimiento. Entre los monolingües, se encuentran construcciones de agradecimiento más complejas que solamente la palabra individual gracias, especialmente en la situación con el profesor (ejemplos 18a-d). Típicamente aparece con la conjugación del verbo agradecer y con la frase de antemano.

(18a) Agradeciendo de antemano sus atenciones me despido de usted respetuosamente y en espera de su favorable respuesta. (nativo, 25)

(18b) Le agradezco de antemano y espero su respuesta. (nativo, 16)

(18c) Espero que usted pueda comprender mi situación y de antemano le doy las gracias. (nativo, 11)

(18d) De antemano gracias. (nativo, 22)

Por otra parte, entre los $\mathrm{HH}$, a veces se incluye el agradecimiento en forma del verbo (ejemplo 19a), pero en la mayoría se prefiere el uso de la palabra gracias suelta, aún en la situación de mayor formalidad (19a-c).

(19a) Tengo una emergencia familiar y no voy a poder entregar el proyecto a tiempo. Le agredeceria mucho si me diera la oportunidad de entregarlo una semana despues. Gracias por su tiempo y su ayuda. $(\mathrm{HH}, 19)$

(19b) Hola Profesor de economía... Le quiero preguntar si es posible darme una extension para poder entregar este proyecto. Si quiere mas informacion sobre la emergencia dejeme saber y le explicare mas en detalle si gusta. Gracias. $(\mathrm{HH}, 1)$

(19c) De nuevo lo siento mucho y desculpeme por esto. Si desea hablar conmigo en persona porfavor no se detenga en hacerlo. Muchas gracias y espero oir de usted pronto. $(\mathrm{HH}, 6)$

Normas (ISSN: 2174-7245) | 


\title{
normas
}

Te lo pido por favor: estrategias de cortesía de hablantes de herencia del español mexicano | Chelsea Escalante

Otra diferencia entre los grupos es que en el contexto más formal, los nativo-hablantes emplean las estrategias de la impersonalización (ejemplos 20a-b) y la nominalización (ejemplo 21) un total de 21 veces, mientras que los $\mathrm{HH}$ (ejemplo 22) utilizan las mismas estrategias solamente en 8 ocasiones.

\begin{abstract}
(20a) Por medio de la presente me dirijo a usted por el motivo de que se me ha presentado una emergencia familiar (nativo, 19).

(20b) Oye, se me descompuso el carro ahorita que iba pal' la fiesta. puedes pasr por mi? (nativo, 7)

(21) El motivo del presente mail es para primeramente saludarle, y en segundo lugar para pedir una extensión del plazo de una semana en la entrega del proyecto de economía queme fue encomendado. La razón de la solicitud obedece a una emergencia familiar importante que impide la entrega del documento en la fecha especificada. Ruego disculpe el importuno y haga valer mi solicitud. Espero respuesta a la petición. (nativo, 15) (22) Aqui todo va bien, pero ya se me va a cabar el dinero de la cuenta y todavía me faltan unos recibos pendientes por pagar. $(\mathrm{HH}, 7)$
\end{abstract}

Además de ser estos marcadores de cortesía, estas estrategias sirven como otra función en el campo de la escritura académica. Tanto la nominalización como la impersonalización se consideran «metáforas gramaticales»: herramientas que permiten al hablante tomar la postura objetiva de un experto en el tema (Colombi, 2003). Como tal, las dos estrategias son útiles a la hora de enseñar competencia académica ("advanced literacy») - tema central de las clases de lenguas de herencia. Si se enseñan explícitamente estas construcciones como estrategias de cortesía, los alumnos podrían transferir el conocimiento de ellas a sus ensayos expositivos y ampliarían su registro académico.

\section{DISCUSIÓN E IMPLICACIONES PEDAGÓGICAS}

En esta investigación se pretendió encontrar y entender los patrones de competencia pragmática por parte de los $\mathrm{HH}$ en cuatro situaciones de poder y distancia social diferentes: $(+P,+D),(+P,-D)$, $(-P,+D)$, y (-P, -D). Los resultados proveen una abrumadora evidencia que apoya la idea de que los hablantes avanzados de español como lengua de herencia sí poseen competencia pragmática en la formación de sus peticiones. En los cuatro análisis de cortesía se demuestra una sensibilidad a los factores de poder y distancia social, lo cual indica que los $\mathrm{HH}$ utilizan diferentes herramientas para navegar el sistema pragmático de su lengua dependiendo del nivel de poder y distancia en que se encuentran. En el análisis del modelo estadístico de los primeros dos análisis - de tratamiento y de formación del acto principal de la petición - no se encontró evidencia que apoye que los HH se comporten de manera diferente que los nativos. A diferencia de lo que encontró Brown (1975), quien reportó que los hablantes bilingües de ascendencia mexicana en Arizona usan usted con sus padres en una tasa que es el doble que la que existe entre los monolingües mexicanos, nuestro estudio encontró que los dos grupos prefieren el uso de usted en la situación de mayor poder y distancia social y tú en las otras situaciones. A diferencia de lo que encontró Félix-Brasdefer (2005), encontramos que las construcciones indirectas convencionales son las preferidas en todas las situaciones de poder y distancia (pero señalan su sensibilidad estilística con otras herramientas). Esto sugiere que los $\mathrm{HH}$ en el estado de Arizona han adquirido las normas de la zona monolingüe geográficamente más cercana con respecto al uso de tú y usted y al nivel de franqueza usado en la formación de las peticiones.

En los otros dos análisis - los que medían las estrategias de cortesía positiva y negativa - sí se encontraron diferencias significativas entre los bilingües y los nativo-hablantes en el modelo estadístico. Como tal, los resultados también apoyan los estudios previos (véase Finestrat y Potowski 2016; Pinto y Raschio, 2007; Showstack, 2016a) que muestran evidencia de un estilo 


\section{normas}

Te lo pido por favor: estrategias de cortesía de hablantes de herencia del español mexicano | Chelsea Escalante

intercultural en la producción de la petición por los HH. Las diferencias más notables son que los $\mathrm{HH}$ emplean una menor cantidad de estrategias de cortesía en general que los nativos; los HH usan la alternancia de código como marcador gregario innovador en un grado mayor; emplean más la estrategia de dar razones en comparación a otras estrategias; dan gracias de forma más sencilla; y tienen menos instancias de la nominalización y la impersonalización en sus peticiones.

Aparte de subrayar la importancia de la instrucción explícita de la pragmática, como han hecho varios investigadores (Félix-Brasdefer, 2005; 2006; 2007; Mwinyelle, 2005), estos resultados informan sobre una aproximación pedagógica a la enseñanza de ella. Basado en los resultados, los $\mathrm{HH}$ ya tienen competencia al nivel del monolingüe de las estructuras más obvias de cortesía en español: tú vs. usted y el uso de peticiones directas (dámelo) versus indirectas (¿me lo das, por favor?). Además tienen en su repertorio el conocimiento de una variedad de estrategias positivas y negativas que pueden implementar para hablar con los interlocutores de diferentes grados de poder y distancia social. Sin embargo, podrían ampliar su conocimiento y uso de las estrategias de cortesía positiva y negativa para aproximarse más al estándar de la comunidad monolingüe geográficamente más cercana. Dado el uso común del correo electrónico hoy en día, sería relativamente fácil encontrar ejemplos de las prácticas discursivas de diferentes comunidades de habla y compartirlos en clase para crear conciencia en los alumnos sobre la variabilidad geográfica y contextual de normas de cortesía. Por ejemplo, como actividad en clase, se podría leer correos electrónicos de diferentes orígenes dirigidos a interlocutores de distintos niveles de poder y distancia social. Se puede discutir y analizar las estrategias vistas, y luego practicar con la formación de sus propios correos de acuerdo a las normas del lugar de interés. Como destaca Showstack (2016a), en esta instrucción, es importante evitar la representación de la pragmática como un conjunto de reglas. Al contrario, la autora sugiere que se debe discutir con los alumnos que las normas pragmáticas en uso en las comunidades hispanohablantes de los EE.UU. podrían ser diferentes de las normas en uso en otra región hispanohablante, y que el uso de determinadas formas pragmalingüísticas depende de una variedad de aspectos contextuales.

Las actividades que se centran en el campo de la pragmática tienen el potencial de contribuir a las cuatro metas de la educación de lenguas de herencia: (1) mantener la lengua materna; (2) adquirir la variedad 'estándar'; (3) expandir el repertorio bilingüe; y (4) transferir herramientas de literacidad (habilidades de lecto escritura) (Valdés, 2000). Al estudiar las normas pragmáticas de diferentes situaciones, sería más probable que el hablante use el idioma en mayores contextos, lo que ayuda al mantenimiento de la lengua. También se estaría cumpliendo con la meta (2), adquirir la variedad "estándar», porque los alumnos de HH podrán aprender las normas monolingües de diferentes regiones geográficas. Tercero, estarían expandiendo el reportorio bilingüe a través del aprendizaje de estrategias más adecuadas en situaciones formales. Por último, estos alumnos podrían transferir el conocimiento de algunas estrategias al área de la escritura académica, especialmente la nominalización y la impersonalización, incrementando a la misma vez el nivel de literacidad en otro contexto. Además de ayudar con el cumplimiento de las metas, otro beneficio de la enseñanza explícita es que se considera que el aula es un lugar más seguro para aprender y practicar la pragmática que «el mundo real», dado que se puede experimentar con las consecuencias de comunicarse de distintas maneras y aprender de ellas sin cometer los errores en situaciones verdaderas donde hay mayor posibilidad de malentendidos y consecuencias sociales (Bardovi-Harlig y Mahan-Taylor, 2003). 


\section{normas}

Te lo pido por favor: estrategias de cortesía de hablantes de herencia del español mexicano | Chelsea Escalante

\section{LIMITACIONES Y DIRECCIONES FUTURAS}

En este estudio, se ha investigado la competencia pragmática de 30 hablantes del español mexicano como lengua de herencia en cuanto a su realización de la petición. Como punto de referencia, se comparó la realización de estas peticiones con las de 30 nativo-hablantes de español del norte de México con la intención de ver las semejanzas y diferencias en el comportamiento de cada grupo. La aproximación contrastiva no es nueva en los estudios de lenguas de herencia; tradicionalmente, uno de los objetivos de estos cursos era que los estudiantes aprendieran a hablar como monolingües y alcanzaran el dominio de una variedad estándar idealizada de la lengua meta (Showstack, 2016a). Como tal, mucha de la literatura disponible sobre los HH discute las diferencias que hay su habla en comparación con los nativo-hablantes o se habla de su competencia en términos de adquisición incompleta (véase Lipski, 1993; Montrul, 2008; 2009; 2010; Montrul, Foote, y Perpiñán, 2008; Montrul y Perpiñán, 2011; Polinsky, 2006; 2011; Silva-Corvalán, 1994, 2003, entre otros). Aunque este análisis contrastivo ha enriquecido nuestro entendimiento del bilingüe en aspectos léxico-semánticos, morfo-sintácticos, sociolingüísticos, pragmáticos, psicolingüísticos y pedagógicos, no viene sin algunas desventajas. En particular, la comparación de los bilingües con los monolingües sugiere que los $\mathrm{HH}$ no han adquirido la lengua al mismo nivel que los monolingües y que necesitan mejorar para llegar a ser un hablante "más completo». Sin embargo, las aproximaciones contemporáneas en la enseñanza de español se han distanciado de esta perspectiva (véase Canagarajah, 2011b; Correa, 2016; Faulstich Orellana, Lee Martínez, 2010; Leeman, 2014, Showstack, 2016b; Wei y García, 2016, entre otros) y han abandonado el concepto de la diglosia tradicional abogando por una crítica que enfatiza las prácticas translingüísticas de los bilingües (véase García, 2013). Esta aproximación afirma que la comparación del HH con algún estándar monolingüe idealizado no es recomendable porque el sistema bilingüe es completamente diferente al sistema monolingüe. En el área de la pragmática en particular, Showstack (2016a) destaca que puede ser problemático comparar a los $\mathrm{HH}$ con los nativos porque no está claro que los $\mathrm{HH}$ necesariamente quieran seguir las normas monolingües ni que las practicas discursivas de una comunidad sean directamente aplicables a otra. En este trabajo se intentó mitigar ese efecto al estudiar la norma monolingüe de la zona geográficamente más cercana a Arizona y al incluir los $\mathrm{HH}$ de solamente la variedad mexicana. No obstante, todavía se podría cuestionar la aplicabilidad de las prácticas monolingües a contextos bilingües.

Si tenemos esto en cuenta, los futuros estudios sobre la pragmática de los $\mathrm{HH}$ que quieran tomar una posición más crítica podrían basarse en la idea del hablante como experto de las normas de su comunidad. Las investigaciones etnográficas, por ejemplo, que exploran más a fondo las prácticas discursivas de una comunidad, junto con la negociación de los significados de ellas, podrían aportar datos importantes sobre cómo los HH llegan a tener las herramientas para llevar a cabo las funciones pragmalingüísticas dentro de su comunidad de habla.

\section{REFERENCIAS BIBLIOGRÁFICAS}

Adelman, Mara y Myron Lustig (1981): «Intercultural communication problems as perceived by Saudi Arabian and American managers", International Journal of Intercultural Relations, 5, 4, 349-363.

Arellano, Silvia (2000): «A Hierarchy of Requests in California Spanish: Are Indirectness and Mitigation Polite?» en Roca, Ana, ed., Research on Spanish in the U.S., Somerville, MA, Cascadilla Press, 319-332.

Ballesteros Martín, Francisco José (2001): «La cortesía española frente a la cortesía inglesa. Estudio pragmalingüístico de las exhortaciones impositivas», Estudios ingleses de la Universidad Complutense, 9, 171-207. 
Te lo pido por favor: estrategias de cortesía de hablantes de herencia del español mexicano | Chelsea Escalante

Bardovi-Harlig, Kathleen y Rebecca Mahan-Taylor (2003): «Introduction» en Bardovi-Harlig, Kathleen y Rebecca MahanTaylor, eds., Teaching pragmatics, Washington, D.C., Department of State, 37-39.

Blommaert, Jan (1988): «Intercultural communication and objects of adaption», IPrA Working Document, 3, 61-70.

Blum-Kulka, Shoshana (1989): «Playing it safe: The role of conventionality in indirectness», en Blum-Kulka, Shoshana, Juliane House y Gabriele Kasper, eds., Cross-cultural pragmatics: Requests and apologies [Advances in Discourse Processes 31], Norwood, NJ, Ablex, 37-70.

Brown, Dolores (1975): "The use of "Tú" and "Usted” with Parents by Some Mexican American Students", Hispania, 58, 1, 126-129.

Brown, Penelope y Stephen Levinson (1987): Politeness: Some universals in language usage. Cambridge, Cambridge University Press.

Canagarajah, Suresh (2011): «Translanguaging in the classroom: Emerging issues for research and pedagogy», Applied Linguistics Review, 2, 1, 1-28.

Colombi, María Cecilia (2003): «Un enfoque funcional para la enseñanza del ensayo expositivo», en Roca, Ana y María Cecilia Colombi, eds., Mi lengua: Spanish as Heritage Language in the United States, Washington, D.C., Georgetown University Press, 78-95.

Correa, Maite (2016): «Critical approaches to Heritage Language Learning: From Linguistic Survival to Resistance and Action», en Trifonas, Peter Pericles y Themistoklis Aravossitas, eds., Handbook of Research and Practice in Heritage Language Education, New York, Springer, 1-14.

Curcó, Carmen (1998). «¿No me harías un favorcito? Reflexiones en torno a la expresión de la cortesía verbal en el español de México y el español peninsular», en Haverkate, Henk, Gijs Mulder y Carolina Maldonado, eds., La Pragmática Lingüística del Español: Recientes Desarrollos, Amsterdam, Rodopi, 129-171.

Doi, Takeo (1981): The anatomy of dependence. Tokyo, Kondansha International.

Dressler, Wolfgang (1982): «Acceleration, retardation, and reversal in language decay?», en Cooper, Rober, ed., Language Spread, Bloomington, IN, Indiana University Press, 321- 336.

Dressler, Wolfgang (1988): «Language Death», en Newmeyer, Frederick, ed., Linguistics: The Cambridge Survey [Volume 4: Language: The Socio-cultural Context], Cambridge, Cambridge University Press, 184-191.

Dumitrescu, Domnita (2006): «Agradecer en una interlengua: Una comparación entre la competencia pragmática de los estudiantes nativos y no nativos del español en California, Estados Unidos», en Murillo Medrano, Jorge, ed., Actos de habla y cortesía en distintas variedades del español: perspectivas teóricas y metodológicas. Actas del Segundo Coloquio Internacional del Programa EDICE, San José, Universidad de San José de Costa Rica y EDICE.

Færch, Claus y Gabriele Kasper (1989): «Internal and external modification in interlanguage request realization», en BlumKulka, Shoshana, Juliane House y Gabriele Kasper, eds., Cross-cultural pragmatics, Norwood, NJ, Ablex, 221-247.

Faulstich Orellana, Marjorie, Clifford Lee y Danny Martínez (2010): «More than Just a Hammer: Building Linguistic Toolkits», Issues in Applied Linguistics, 18, 2, 181-187.

Finestrat, Irene y Kim Potowski (2016): «Requests and Refusals Among Bilingual Mexican- Americans», 8th International Workshop on Spanish Sociolinguistics, San Juan, Puerto Rico, 14 abril. Felix-Brasdefer, J. César (2005): «Indirectness and Politeness in Mexican Requests», Selected proceedings of the 7th Hispanic Linguistics Symposium, Somerville, MA, Cascadilla, 66- 78.

Félix-Brasdefer, J. César (2006): «Linguistic Politeness in Mexico: Refusal strategies among male speakers of Mexican Spanish», Journal of Pragmatics, 38, 2158-2187.

Felix Brasdefer, J. César (2007): «Pragmatic development in the Spanish as a FL classroom: A cross-sectional study of learner requests», Intercultural Pragmatics, 4, 2, 253-286.

Ferguson, Charles (1981): «The structure and use of politeness formulas», en Coulmas, Florian, ed., Conversational routine, The Hague: Mouton.

García, Ofelia (2013): «El papel de translenguar en la enseñanza del español en los Estados Unidos», en Dumitrescu, Domnita y Gerardo Piña-Rosales, eds., El español en los Estados Unidos: E pluribus unum? Enfoques multidisciplinarios, New York, Academia Norteamericana de la Lengua Español, 353-373.

Goffman, Erving (1967): Interaction ritual. New York: Anchor Books.

Goffman, Erving (1972): «On face-work: An analysis of ritual elements in social interaction», en Laver, John y Sandy Hutcheson, eds., Communication in face-to-face interaction, Harmondsworth, Penguin, 319-346.

Gu, Yueguo (1990): «Politeness phenomena in modern Chinese», Journal of Pragmatics, 14, 237-257.

Ide, Sachiko (1989): «Formal forms and discernment: Two neglected aspects of linguistic politeness», Multilingua, 8, 223248.

Isurin, Ludmila y Tanya Ivanova-Sullivan (2008): «Lost in Between: The Case of Russian Heritage Speakers», Heritage Language Journal, 6, 1, 72-104.

Kagan, Olga (2005): «In support of a proficiency-based definition of heritage language learners: A case of Russian», International Journal of Bilingual Education and Bilingualism, 8, 2/3, 213-221. 
Te lo pido por favor: estrategias de cortesía de hablantes de herencia del español mexicano | Chelsea Escalante

Kagan, Olga (2012): «Intercultural Competence of Heritage Language Learners: Motivation, Identity, Language Attitudes, and the Curriculum", Proceedings of the Second Intercultural Competence Conference, 2, 72-84.

Kondo-Brown, Kimi (2003): «Heritage language instruction for post-secondary students from immigrant backgrounds», Heritage Language Journal, 1, 1, 1-29.

Lipski, John (1993): «Creoloid Phenomena in the Spanish of Transnational Bilinguals», en Roca, Ana y John Lipski, eds., Spanish in the United States, Berlin, Mouton, 155-182.

Matsumoto, Yoshiko (1989): «Politeness and conversational universals - observations from Japanese», Multilingua, 8, 207221.

Montrul, Silvina (2002): «Incomplete Acquisition and Attrition of Spanish Tense/Aspect Distinctions in Adult Bilinguals», Bilingualism: Language and Cognition, 5, 39-68.

Montrul, Silvina (2008): Incomplete acquisition in bilingualism: Re-examining the age factor, Amsterdam: John Benjamins.

Montrul, Silvina (2009): «Incomplete acquisition of Tense-Aspect and Mood in Spanish heritage speakers», The International Journal of Bilingualism, 13, 239-269.

Montrul, Silvina (2010): «How similar are L2 learners and heritage speakers? Spanish clitics and word order», Applied Psycholinguistics, 31, 167-207.

Montrul, Silvina (2012): «Is The Heritage Language Like A Second Language?», EUROSLA Yearbook, 12, 1, 1-29.

Montrul, Silvina, Rakesh Bhatt y Roxana Girju (2015): «Differential Object Marking in Spanish, Hindi and Romanian as heritage languages», Language, 91, 3, 1-47.

Montrul, Silvina y Melissa Bowles (2009): «Back to basics: Differential Object Marking under incomplete acquisition in Spanish heritage speakers", Bilingualism: Language and Cognition, 12, 3, 363-383.

Montrul, Silvina y Melissa Bowles (2010): «ls grammar instruction beneficial for heritage language learners? Dative case marking in Spanish», Heritage Language Journal, 7, 1, 47- 73.

Montrul, Silvina, Rebecca Foote y Silvia Perpiñán (2008): «Gender Agreement in Adult Second- Language Learners and Spanish Heritage Speakers: The Effects of Age and Context of Acquisition", Language Learning, 58, 3, 503-53.

Montrul, Silvina y Silvia Perpiñán (2011): «Assessing Differences and Similarities between Instructed Second Language Learners and Heritage Language Learners in Their Knowledge of Spanish Tense-Aspect and Mood (TAM) Morphology», Heritage Language Journal, 8, 1, 90-133.

Mwinyelle, Jerome Banaya (2005): The acquisition of Pragmatic Competence in an L2 Classroom: Giving Advice in Spanish [Tesis doctoral], The University of Texas at Austin.

Pinto, Derrin (2012): «Pragmatics and Discourse: Doing Things with Words in Spanish as a Heritage Language», en Beaudrie, Sara y Marta Fairclough, eds., Spanish as a Heritage Language in the United States: The State of the Field, Washington, DC, Georgetown University Press, 121-138.

Pinto, Derrin y Richard Raschio (2007): «A Comparative Study of Requests in Heritage Speaker Spanish, L1 Spanish, and L1 English», International Journal of Bilingualism, 11, 2, 135-155.

Polinsky, María (2006): «Incomplete acquisition: American Russian», Journal of Slavic Linguistics, 14, $191-262$.

Polinsky, María (2008a): «Heritage language narratives», en Brinton, Donna, Olga Kagan y Susan Bauckus, eds., Heritage language education. A new field emerging, New York, Routledge, 149-164.

Polinsky, María (2008b): «Russian gender under incomplete acquisition», Heritage Language Journal, 6, 1, 40-71.

Polinsky, María (2008c): «Without aspect», en Corbett, Greville y Michael Noonan, eds., Case and grammatical relations, Oxford, Oxford University Press, 263-282.

Polinsky, María (2011): «Reanalysis in adult heritage language: A case for attrition», Studies in Second Language Acquisition, 33, 305-328.

Polinsky, María y Olga Kagan (2007): «Heritage languages: In the 'wild' and in the classroom», Language and Linguistics Compass, 1, 5, 368-95.

Reznicek-Parrado, Lina María (2013): Pedagogía de hablantes de herencia: implicaciones para el entrenamiento de instructores en el nivel universitario [Tesis de master], University of Nebraska-Lincoln.

Sánchez-Muñoz, Ana (2007): «Style Variation in Spanish as a Heritage Language: A Study of Discourse Particles in Academic and Non-Academic Registers", en Potowski, Kim y Richard Cameron, eds., Spanish in Contact: Policy, Social and Linguistic Inquiries, Amsterdam, John Benjamins, 153-171.

Sankoff, Gillian (2001): «Linguistic Outcomes of Language Contact», en Trudgill, Peter, J. K. Chambers y Natalie SchillingEstes, eds., Handbook of Sociolinguistics, Oxford, Basil Blackwell, 638-668.

Scollon, Ron y Susan Wong Scollon (2001): Intercultural communication, Malden, MA, Blackwell Publishers, 2.a ed.

Showstack, Rachel (2016a): «La pragmática transcultural de los hablantes de herencia de español: análisis e implicaciones pedagógicas", Journal of Spanish Language Teaching, 3, 2, 143-156.

Showstack, Rachel (2016b): «Stancetaking and Language Ideologies in Heritage Language Learner Classroom Discourse», Journal of Language, Identity and Education, 1-14.

Silva-Corvalán, Carmen (1994): Language Contact and Change: Spanish in Los Angeles, Oxford, Oxford University Press. 


\section{normas}

Te lo pido por favor: estrategias de cortesía de hablantes de herencia del español mexicano | Chelsea Escalante

Silva-Corvalán, Carmen (2003): «Linguistic Consequences of Reduced Input in Bilingual First- Language Acquisition», en Montrul, Silvina y Francisco Ordóñez, eds., Linguistic Theory and Language Development in Hispanic Languages, Somerville, MA, Cascadilla Press, 375-397.

Tannen, Deborah (1985): «Cross-cultural communication» en Teun Van Dijk, ed., Handbook of discourse analysis, London, Academic Press, 203-215.

Trosborg, Anna (1995): Interlanguage Pragmatics: Requests, Complaints, and Apologies, Berlin, Mouton de Gruyter.

Valdés, Guadalupe (1981): «Pedagogical Implications of Teaching Spanish to the Spanish- Speaking in the United States», en Valdés, Guadalupe, Anthony Lozano y Rodolfo García-Moya, eds., Teaching Spanish to the Hispanic Bilingual: Issues, Aims, and Methods, New York, Teachers College Press, 3-20.

Valdés, Guadalupe (1981): «Codeswitching as Deliberate Verbal Strategy: A Microanalysis of Direct and Indirect Requests among Bilingual Chicano Speakers», en Durán, Richard, ed., Latino Language and Communicative Behavior, Norwood, NJ, Ablex, 95-107.

Valdés, Guadalupe (2000): «Bilingualism and Language Use Among Mexican Americans», en Sandra Lee McKay y SauLing Cinthya Wong, eds., New Immigrants in the United States: Readings for Second Language Educators, Cambridge, Cambridge University Press, 113-146.

Watts, Richard (1989): «Relevance and relational work: linguistic politeness and political behavior», Multilingua, 8, 2/3, 131-166.

Wei, Li y Ofelia García (2016): «From Researching Translanguaging to Translanguaging Research», en King, Kendall, YiJu Lai y Stephen May, eds., Research Methods in Language and Education [Encyclopedia of Language and Education], Cham, Suiza, Springer International Publishing, 1-14.

Wierzbicka, Anna (1985a): «Different cultures, different languages, different speech acts», Journal of Pragmatics, 9, 145178.

Wierzbicka, Anna (1985b): «A semantic metalanguage for crosscultural comparison of speech acts and speech genres», Language in Society, 14, 491-514.

Wierzbicka, Anna (1991): Cross-cultural pragmatics. The semantics of human interaction. Berlin, Mouton de Gruyter. 